\title{
Variation in Eranthis hyemalis, Ficaria verna, and other Members of the Ranunculaceae, with Special Reference to Trimery and the Origin of the Perianth.
}

\author{
BY \\ E. J. SALISBURY, D.Sc., F.L.S., \\ Lecturer in Botany, East London College, University of London.
}

With twenty Figures in the Text and Tables I-X.

\begin{abstract}
TE observations embodied in the present paper were made with a view I to obtaining more detailed information than was available regarding the structure of 'indefinite' flowers. The results seemed sufficiently interesting to warrant their publication, since they appear to justify certain conclusions regarding the character of the perianth in the Ranunculaceae.

The material employed has been derived from several widely separated localities, in order, as, far as possible, to ensure the inclusion of extremes. Reliance has, however, been chiefly placed on a detailed examination of numerous specimens from one or two habitats.
\end{abstract}

\section{Eranthis hyemalis, Salisbury.}

(a) The structure of the normal flower.

Examination of nearly four hundred specimens of Eranthis hyemalis shows that by far the greater number exhibit a coloured perianth of six members disposed in two whorls of three members each, thus corresponding to the one-third phyllotaxy of the foliage and scale-leaves (cf. Irmisch, 1860). As the flower emerges from the soil (Salisbury, 1916 a) it is protected by an involucre of three bracts. These are connate at the base and form a whorl immediately below the flower. A close examination will show that of the three bracts one is completely external, the adjacent member has one margin underlapping and the other overlapping, whilst the third is completely internal. The bracts are thus arranged in a spiral which may pass either in the clockwise or anticlockwise (Fig. 2, C) direction.

Each bract exhibits three principal lobes, which are usually deeply divided, and the whole is supplied by three vascular strands that anastomose

[Annals of Botany, Vol. XXXIII. No. CXXIX. January, Igrg.] 
almost immediately on entering the leaf and again diverge, other smaller veins branching off at the same time (cf. Fig. IO, A-C).

The members of the outer whorl of the perianth are broad and, on removal, show a scar with from five to three vascular bundles (cf. Fig. 2, K), of which the three median bundles are large and the two lateral bundles (not always present) small. The three inner perianth members are narrower than the outer and usually supplied by only three vascular strands (Fig. 2, L), or less commonly by two or even one vascular bundle. In all cases there appears to be but a single strand which leaves the receptacular stele, but this sooner or later gives off two main lateral branches in succession. The variation in the number of bundles, as seen on the scar when a perianth

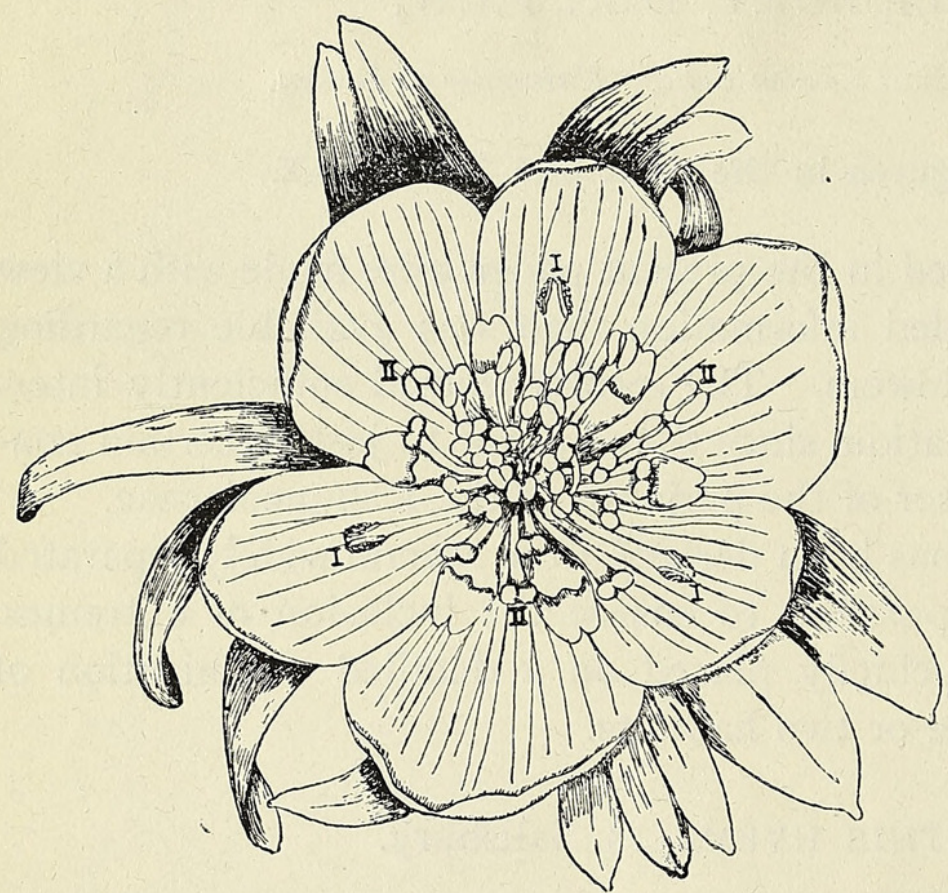

FIG. I. Flower of Eranthis hyemalis. The roman numerals indicate the order of dehiscence. segment is removed, is due to differences in the level at which this trifurcation takes place. Payer (1857) was therefore incorrect in writing, 'Si l'on arrache ces six pétales, on remarque dans chaque cicatrice des trois pétales externes l'empreinte de trois faisceaux fibro-vasculaires, et dans chaque cicatrice des trois pétales internes l'empreinte d'un seul faisceau fibro-vasculaire'. No distinction with regard to the vascular supply can be drawn between the members of the outer and inner

whorl beyond the fact that the broader outer perianth segments usually exhibit more main strands than do the narrower segments of the inner whorl. As we shall see later, supernumerary perianth segments are by no means infrequent, and these usually are narrower even than the inner perianth segments, and, like the latter when they too are narrow, frequently exhibit a scar with only one vascular bundle. Sometimes these supernumerary perianth segments are, however, broader when the bundle branches into three almost at the level of its insertion. The vascular organization of all perianth segments is consequently essentially similar, the minor distinctions being related to their breadth.

Within the perianth there are most commonly found six nectaries, or honey-leaves, which arise in pairs opposite each of the outer perianth segments. The nectary on removal exhibits a scar with a single vascular 
bundle (Fig. 2, M); this passes up the stalk, but on reaching the body of the nectary branches into three strands which traverse the bilobed dorsal lip.

The androecium consists of numerous stamens, the number of which, as shown in the sequel, is very variable-most commonly thirty or some other multiple of three. The stamens are generally found to form a series of radial files, the number of files being commonly double that of the nectaries. There are thus usually twelve radial series, of which six terminate peripherally in a nectary, whilst the remaining six alternate with them; the former

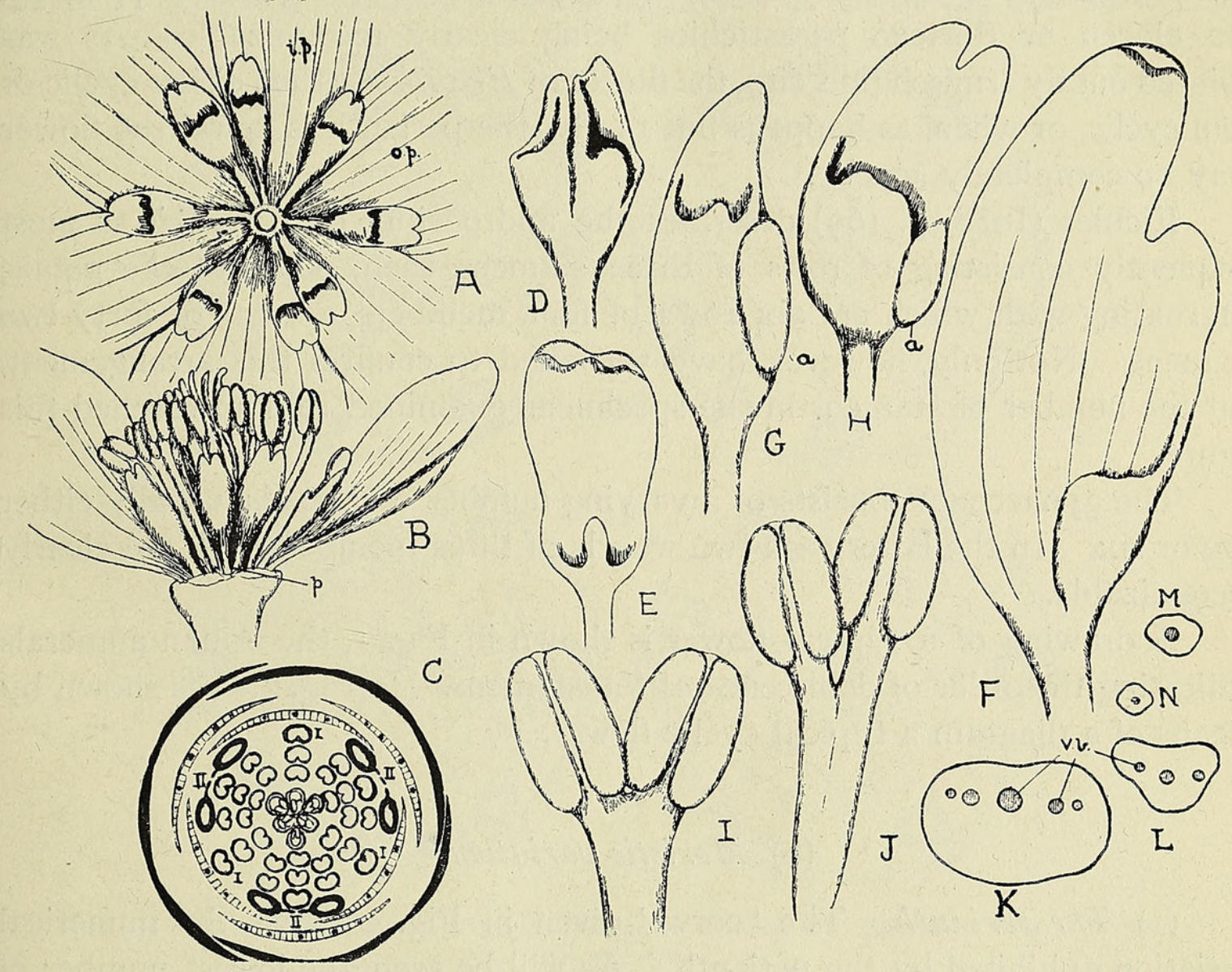

FIG. 2. Eranthis hyemalis. A and B, flowers with the androecium dissected away, showing the paired character of the supernumerary honey-leaves $(p) ; \mathrm{c}$, floral diagram of typical cyclic flower; D, partially bifurcated honey-leaf; E and F, petaloid honey-leaves; $G$ and H, honeyleaves bearing anthers $(a)$; I and J, branched stamens; $\mathrm{K}$, scar of outer perianth segment; L, of inner perianth segment; $\mathrm{M}$, scar of nectary; $\mathrm{N}$, scar of stamen; $v . b$. vascular strand.

each consists typically of two stamens and one nectary and the latter of three stamens. To this arrangement (Fig. 2, C) there are, however, numerous exceptions (Fig. 3), the number of orthostichies being sometimes as many as twenty and not infrequently eleven, thirteen, or fourteen.

By removing a flower, before any of the stamens have dehisced,and placing it in a warm room under a low-power dissecting microscope, the whole sequence of dehiscence can be readily followed. We have confirmed the observation of Irmisch (loc. cit.), that the first stamens to mature are the three situated opposite the inner perianth segments. These are followed by 
the three stamens opposite the outer perianth segments (Fig. I). The three members of each whorl dehisce in rapid succession, followed after a shorter or longer interval by those of the next whorl within. The number of stamens, then, and their order of dehiscence, indicates that the androecium is quite commonly whorled, but a pseudo-spiral appearance is brought about by mutual pressure which results in a lateral displacement comparable to that seen in the floating rosettes of Callitriche vernalis or the leaves surrounding the inflorescence of Cyperus alternifolius. In other cases, however, the androecium is obviously spiral, frequently with a divergence of $\frac{2}{11}$ or $\frac{2}{13}$, the eleven or thirteen parastichies being clearly recognizable. As was pointed out by Irmisch (loc. cit.), the flower of Eranthis is then either cyclic or hemicyclic, or when, as happens but rarely, the perianth is spiral the flower may be completely acyclic.

Eichler (1878, p. I69) describes the androecium of Eranthis as most frequently consisting of rows of three stamens each, opposite the petals, alternating with which are six rows of four members, a total of forty-two stamens. Not only, however, have we failed to confirm this arrangement, but the number of stamens in the specimens examined seldom reached this figure.

The gynaeceum consists of a varying number of carpels, usually either five or six. In the latter case two whorls of three members each are clearly recognizable.

A drawing of a typical flower is shown in Fig. I, the roman numerals indicating the order of dehiscence of the stamens. In Fig. 2, C, is shown by means of a diagram a typical cyclic flower.

\section{(b) Meristic variation.}

(I) The perianth. The 'curve' given in Fig. 4 shows the numerical variation exhibited by the perianth. As will be seen, the lowest number of members observed was five, but in such cases, with few exceptions, the place of the sixth member was taken in the outer whorl by a bract. The actual variation, apart from transformation, is then almost entirely in the direction of increase, the maximum number observed being nine. This unilateral charactei of the variation 'curve' for perianth members is frequent, and de Vries (1905, p. 740) in Ranunculus bulbosus has isolated a concealed secondary summit to which this asymmetry is to be attributed.

If a large number of flowers be examined one is struck by the repeated occurrence of perianth members showing all degrees of lobing, examples of which are shown in Fig. 5, E-G, and Fig. 6, C. Nearly every condition, from a mere notch to two almost completely separated halves, has been observed. Most commonly the two lobes lie in the same tangential plane, but less frequently the lobes are large and overlap to a considerable extent. When 
more than six perianth segments are present the increased number of primordia may be regarded as due to a tendency to produce a polymerous perianth of which the bifurcated members are an incomplete expression.

The two antagonistic tendencies, towards trimery and multiplication of parts, have resulted on the one hand in the production of the numerous instances of supernumerary perianth segments, and on the other in the more or less complete fusions exhibited as notched and bilobed structures. That these latter are to be so interpreted seems indicated by the occasional presence of slightly notched perianth segments in which the two halves do

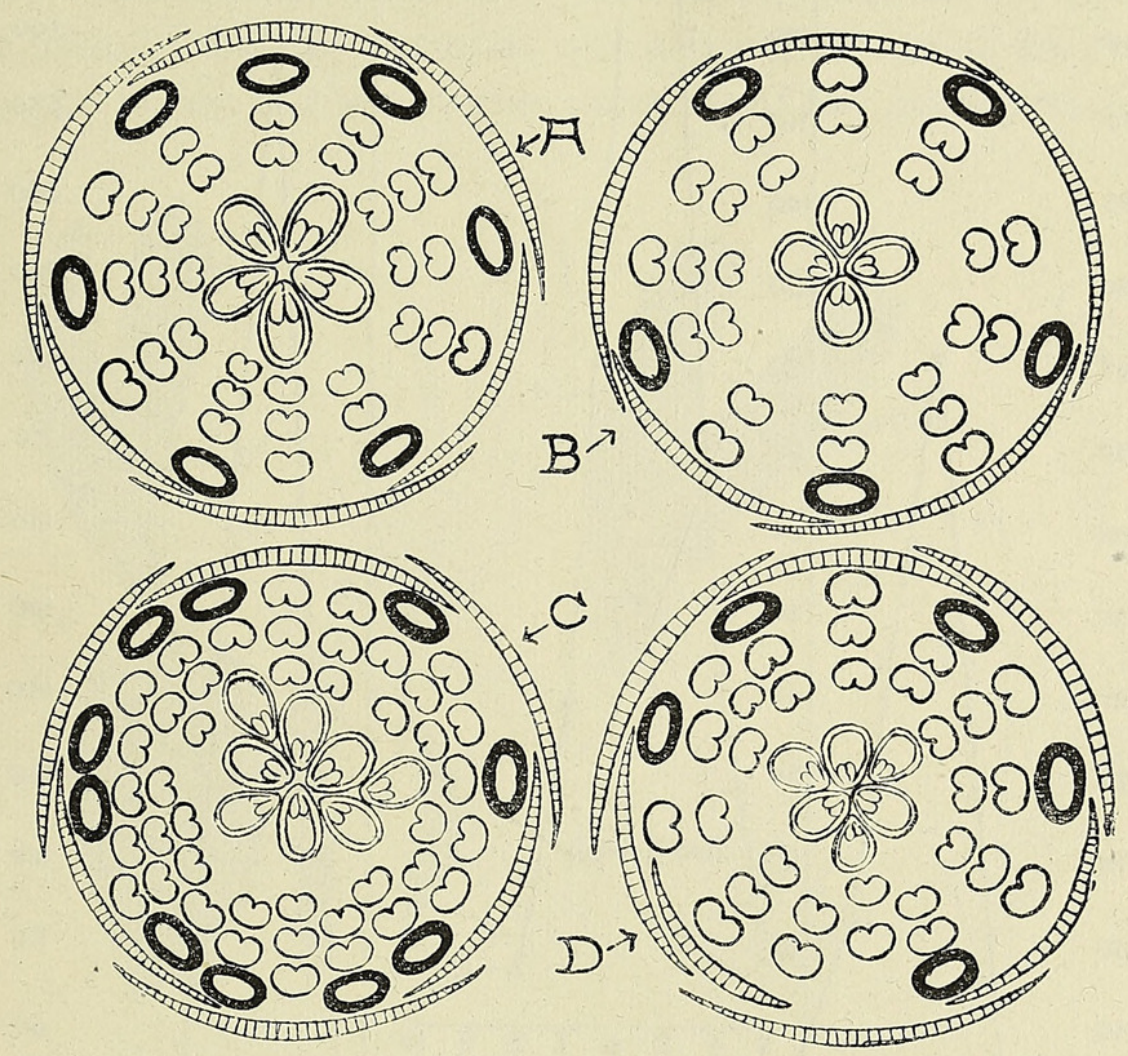

FIG. 3. Eranthis hyemalis. Empirical diagrams showing arrangement of honey-leaves and stamiens.

not stand in the same tangential plane. As a result there is a longitudinal kink where the two halves join that seems best interpreted as due to fusion between two primordia not situated precisely side by side. The rarity of the latter phenomenon is, however, strong presumptive evidence that the fusing pairs of primordia were themselves the product of the congenital fission of a single primordium, and that subsequent fusion has taken place along the original plane of separation; a view supported by the fact that the supernumerary perianth segments are generally much narrower than those normally present (Fig. 5, I). The position which they occupy in the flower is also in agreement with this hypothesis (cf. Fig. 6, A and C). Evidence based on numerical relations will, moreover, be adduced to show that there is no ground for the assumption that the supernumerary members are the result of transformation either of honey-leaves or of stamens. Further, the 
supernumerary perianth segments often lie on the same orthostichy as the honey-leaf, hence to explain the structure of such flowers on this view a double metamorphosis must be assumed, viz. the transformation of the honey-leaf into a petal and of the next stamen within, on the same orthostichy, into a honey-leaf. Again, very rarely a supernumerary perianth segment is present and at the same time the honey-leaves are only five in

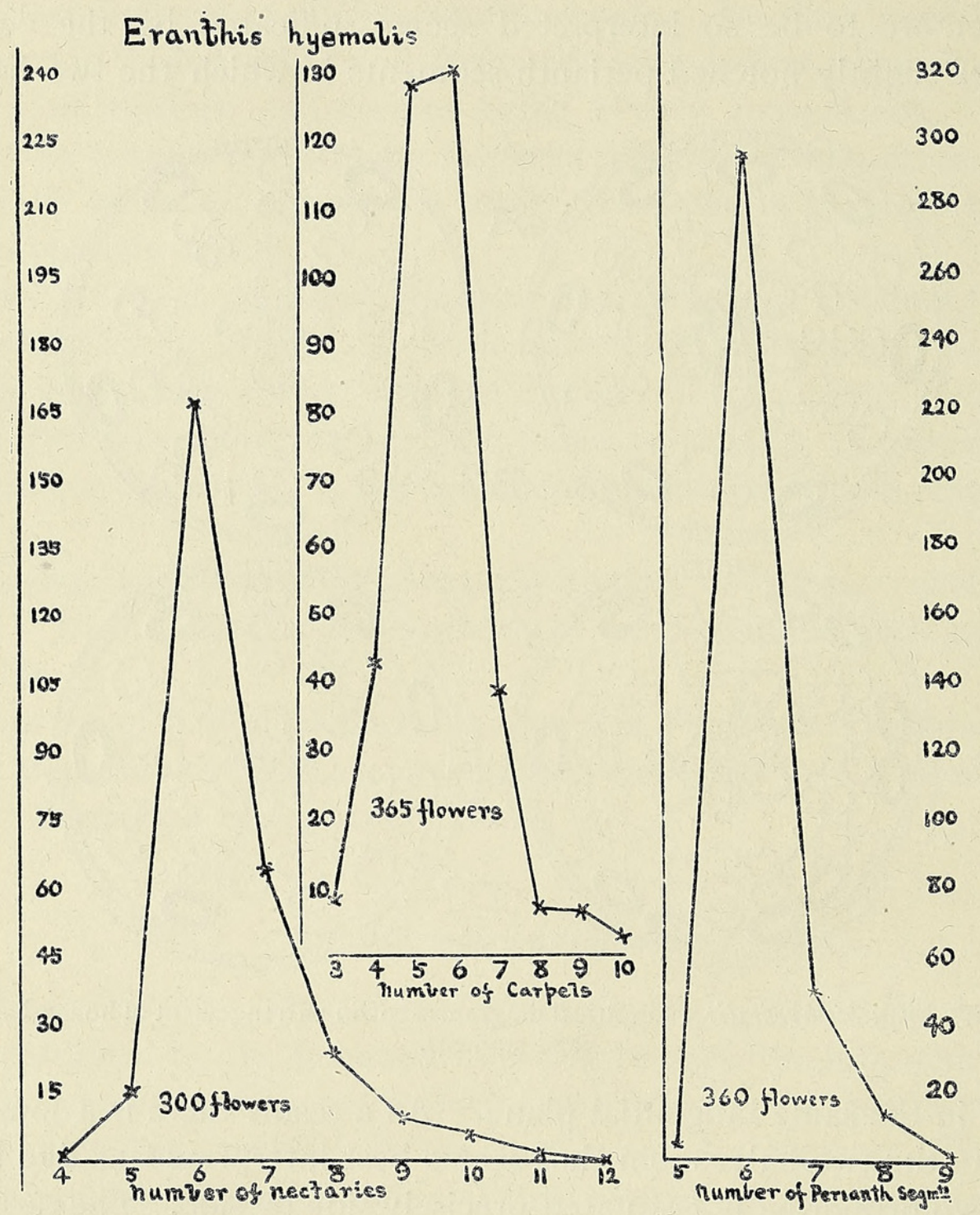

FIG. 4. Variation 'curves' for perianth, honey-leaves, and gynaeceum of E. hyemalis.

number, that on the same orthostichy as the extra perianth segment being absent. This might appear to indicate that, as a rare occurrence, a honeyleaf does become completely transformed, but in the case illustrated in Fig. 3, D, this explanation is not admissible, since it would involve the assumption of one more stamen on this orthostichy than are present on any one of the others. Evidently in such cases the reversion of the nectary to the staminal condition is in some way related to the space-conditions consequent upon the presence of the supernumerary perianth segment. 
In any consideration of the Ranunculaceous perianth the construction which it primitively exhibited is necessarily important, and Eranthis sheds some light on this question. Two conditions are found in Ranunculaceae, viz. the pentamerous and the trimerous, and both are met with in the present species, though the former condition but rarely. As already stated, in most cases where there are only five coloured perianth segments this is due to the transformation of one; but rarely a true pentamerous perianth is found, and where such is the case the five members exhibit a quincuncial arrangement as in typical pentamerous species. It is clear that this condition can easily have been derived from two alternating whorls of three members each if we assume that the member which is half external, half internal, was formed by the fusion of the anterior member of the outer perianth with one

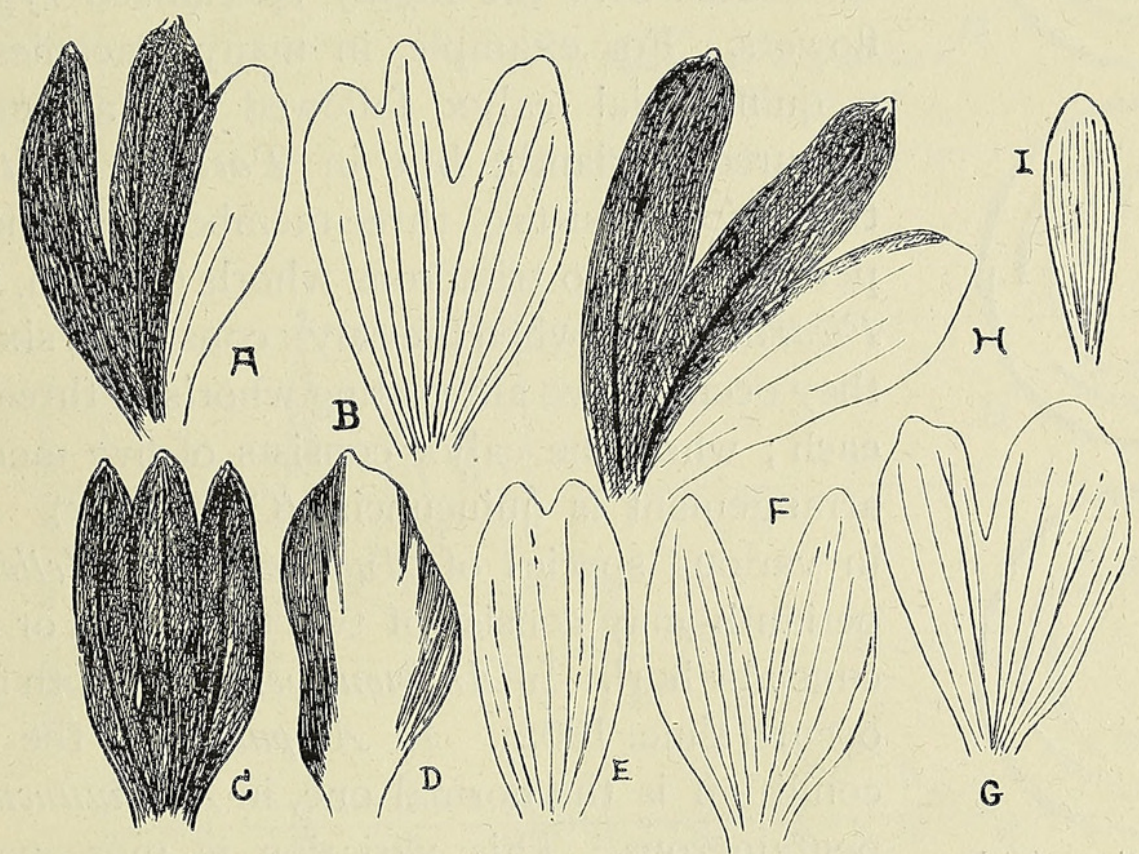

FiG. 5. Eranthis hyemalis. A and B, lobed perianth segments; C, trilobed bract replacing a perianth member; D, partially virescent perianth segment; E-G, lobed perianth segments; H, partially coloured bract; I, supernumerary perianth segment. Green parts indicated by shading.

or other of the lateral members of the inner perianth, according as the flower exhibits a right-handed or left-handed spiral. This would produce the typical quincuncial imbrication. That the perianth member in question has been so derived would seem to be indicated by the fact that in some cases it exhibits six principal veins in place of the usual three. The anterior perianth segment in a quincuncial flower may, moreover, be bilobed, and its attachment is broader than that of the other segments. In Eranthis there can be no question that the pentamerous condition has been derived from the trimerous, and in view of the widespread character of the latter type in related families it may well have been the primitive condition in the Ranales as a whole. Thus we find that in the Nymphaeaceae the genera with the least specialized type of ovary, viz. Cabomba and Brasenia, are trimerous 
throughout, whilst the more specialized ovaries are associated with a multiplication of parts. Moreover, Cabomba and Brasenia exhibit a simpler anatomical structure than the other genera (Gwynne-Vaughan, 1897). A trimerous perianth is also characteristic of the families Anonaceae, Berberidaceae, Lactoridaceae, Lardizabalaceae, Menispermaceae, Magnoliaceae, and Myristicaceae, although several of these orders exhibit the usual derivative of trimery, namely, dimery. Trimery is thus associated with the arboreal

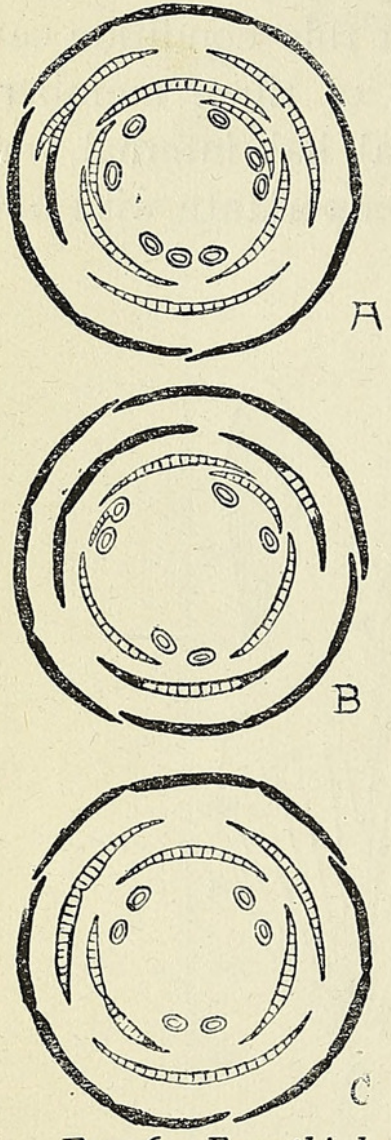

FIG. 6. Eranthis hyemalis. Empirical diagrams showing arrangement of bracts and perianth segments in abnormal flowers. Green parts black, coloured parts shaded. Constrictions indicate lobing.

habit as well as being of widespread occurrence in the Cohort.

In the Ranunculaceae both pentamerous and trimerous flowers occur in the same genus or even in the same species, though pentamery is always associated with the highly specialized zygomorphic flowers. For example, in many Paeonies there is a quincuncial calyx followed by a pentamerous coloured perianth, but in Paeonia whitmanniana the calyx consists of three members and the coloured perianth of two trimerous whorls (Baillon, 1862). In Ficaria verna, when the calyx consists of six members they occur in two alternating whorls of three members each ; when the calyx consists of five members the arrangement is quincuncial (Clos, 1852). Similarly in various species of Anemone and Helleborus the perianth may consist of two trimerous, or one quincuncial whorl. In Anemone nemorosa both conditions occur (Yule, 1902). In $A$. pulsatilla the trimerous condition is the normal one, in $A$. ramunculoides the pentamerous. This variation is, moreover, not restricted to the Ranunculaceae, but occurs also in the Berberidaceae (cf. Eichler, 1875, Bd. I, p. I6) and is even found amongst the stereotyped Monocotyledons. Paris quadrifolia and some members of the Araceae, for example, not infrequently exhibit a single quincuncial whorl (cf. Smith, 1893).

(2) The honey-leaves or nectaries. The honey-leaves vary in number from four to twelve (cf. Figs. 3 and 6). Only one example with four nectaries was encountered, and it is worthy of note that here, as in nine out of the fifteen specimens with only five nectaries, there was no accompanying increase in the number of perianth segments. The reduced number must therefore be attributed to an actual diminution, and is probably due to replacement of one of the pairs of honey-leaves by a single member, and the orientation in such cases fully warrants this suggestion. The increase, up to as many as twelve, is doubtless the outcome of bifurcation of one or more 
of the six honey-leaves usually present. In Fig. $2, \mathrm{~A}$, is shown the arrangement of the honey-leaves in a flower where their number was eight, the gynaeceum and androecium having been dissected away. It will be noticed that four of the honey-leaves are grouped in pairs. The members of each pair here arise in such close proximity as to render their origin from a single rudiment highly probable. The same feature is illustrated from a specimen with seven honey-leaves in Fig. 2, B, the contiguous members being situated at the point marked $p$. In addition specimens of partially bifurcated honeyleaves are occasionally present (Fig. 2, D), the example illustrated being taken from a specimen in which there were also six normal honey-leaves. Cases such as this doubtless indicate a bifurcation of the original rudiment and the subsequent fusion of the two halves. Rarely an additional honey-

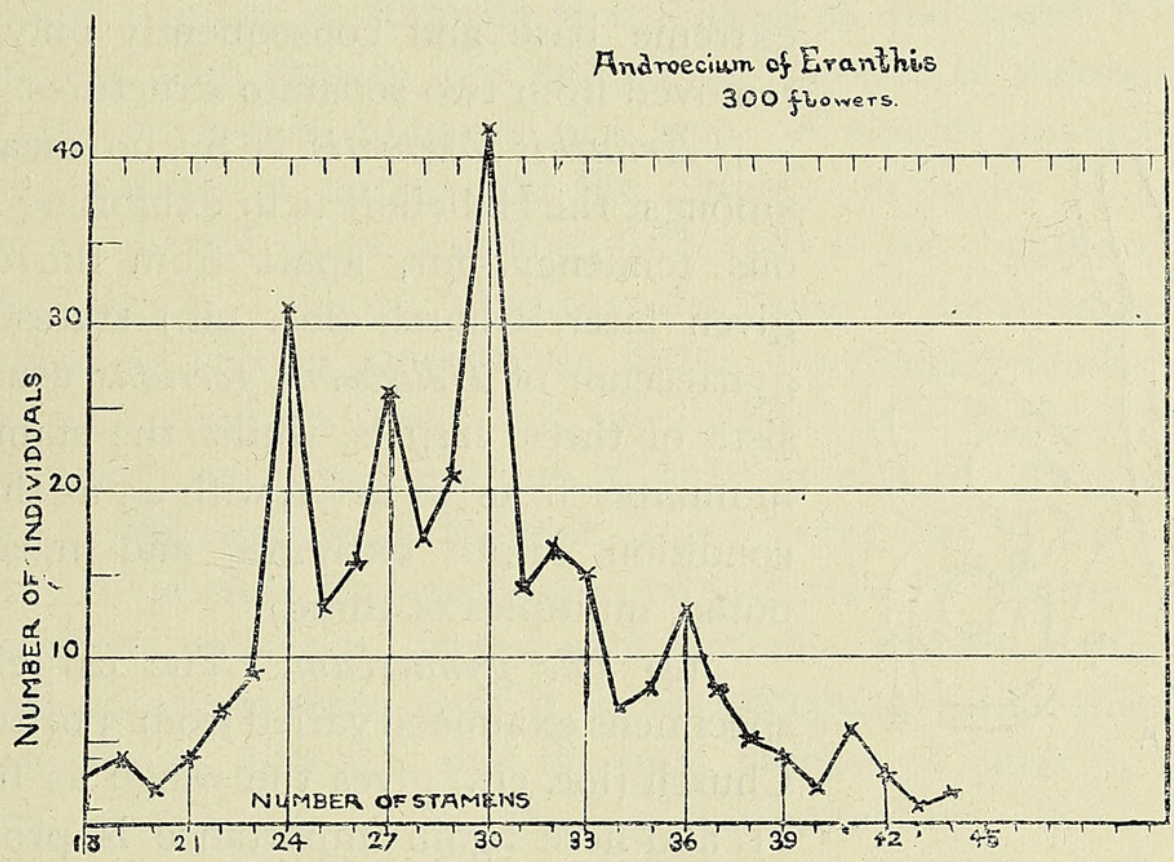

FIG. 7. Eranthis hyemalis. Meristic variation in androecium.

leaf is exhibited that, from its position, is to be regarded as a transformed stamen, since it is situated on the same orthostichy as one of those normally present.

(3) The androecium. The number of stamens ranges from 18 to 44 (cf. Fig. 7), and it is very significant that the lowest number observed should be a multiple of three. Church (1908, pp. I4-16) found that, in the specimens examined by him, the range was from 24 to 39 , with 30 as the usual number. In our specimens the mode was also 30 , whilst a large proportion of flowers had 24 or 27 stamens. It will be noticed that, though the general trend of the 'curve' is of the normal type, there are several maxima associated with numbers which are some multiple of three. Several instances of flowers with forked stamens have been observed (Fig. 2, I and J), and it is of importance to note that in most cases, if the forking be disre- 
garded, the number of stamens is again a multiple of three. Thus in three separate flowers, in each of which one forked stamen was present, the total numbers (inclusive of the forked stamens) were $3 \circ, 33$, and 36 .

Having regard to the method of development of stamens and that the anther is the first part formed, it is evident that these bifurcated examples must have originated as separate papillae, though probably derived by the fission of a single primordium, the two halves of which subsequently fused. Here too, then, as in the perianth, we appear to have the two antagonistic tendencies of multiplication and maintenance of the trimerous condition. The large proportion of individual flowers with 24,27 , and 30 stamens is the outcome of the one, whilst the occurrence of numbers which are not a multiple of three is probably often the outcome of the other. Besides the examples, figured stamens have been found which were branched from the extreme base and consequently only a stage

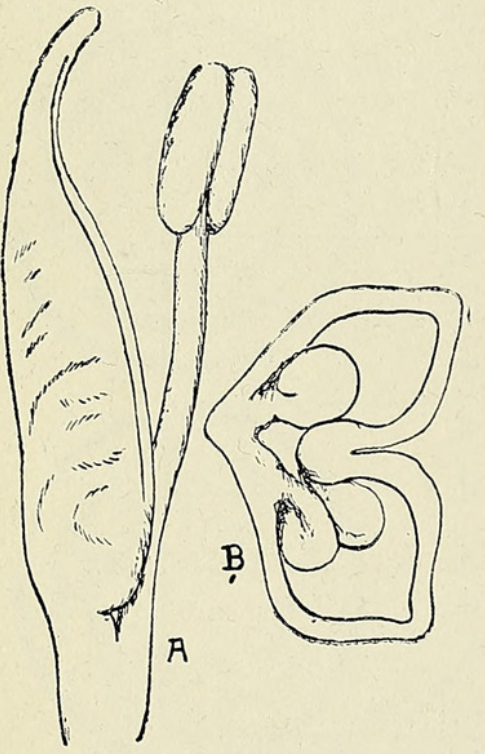

FIG. 8. Fused carpel and stamen of Eranthis hyemalis (A) and branched carpel of Helleborus niger (B).

\section{removed from two separate structures.}

Eranthis hyemalis is by no means alone amongst the Helleboreae in exhibiting a trimerous tendency, for, apart from the examples given later, Church (loc. cit.) states that the gynaeceum of Helleborius foetidus usually consists of three carpels, whilst the stamens vary in number from 30 to 54 , with 45 as the normal condition. Both extremes and mean, be it noted, multiples of three.

(4) The synaeceum. The carpels in the specimens examined varied from 3 to Io, though Church (loc. cit.) gives the range as from 3 to II, and here again importance is probably to be attached to the fact that the minimum number is three. Although six carpels very frequently occur, rather more individuals were found to possess five carpels, though Church (loc. cit.) gives six as the prevailing number. The gynaeceum would thus appear to be more specialized in the direction of reduction than the androecium, a condition that is by no means uncommon in the group. Where six carpels are present, they occur in two whorls of three members each, but where the number is five they appear to be grouped in a single whorl. No case of branching or fusion of carpels has been observed here, but in the closely allied genus Helleborus joined carpels do occur (cf. Fig. 8, B, showing two of the carpels in $H$. niger joined together), which suggests the possibility that departures from the strictly trimerous condition may be the result of congenital fusion of carpel-rudiments. The number of ovules in each carpel ranges from six to ten, but is most commonly eight or seven (cf. Table IV). 


\section{(c) Numerical relations. ${ }^{1}$}

A study of the numerical relations between the different floral regions in the same flower set forth in Tables I-IV establishes the proposition that all the parts of the flower tend to vary at the same time and in the same direction. Thus we find that the larger number of nectaries are associated with more numerous perianth segments, and out of a total of forty-eight flowers with more than six perianth members only five had less than the normal number of nectaries, whilst twenty-nine showed an increase. Such evidence, then, gives no support to the assumption that supernumerary perianth segments represent modified nectaries.

Still more striking is the numerical relation between carpels and stamens, or nectaries and stamens. From Tables II and III it is evident that when the number of stamens is in excess of the mean (viz. 30) the carpels and nectaries usually also exhibit an increase in number over the normal. The converse is, moreover, also true. A similar correlation is seen between the number of carpels and the number of ovules (cf. Table IV), though the number of cases examined (viz. I28) is too small to bring out this relation clearly. Hence, whatever the cause of increase or decrease, whether nutrition or some more subtle factor, it evidently tends to operate in a similar way upon the production of all the organs of the flower. The facile explanation sometimes resorted to, that increase of one type of organ takes place at the expense of another, is not borne out by the facts. On the contrary, it is clear that each type of structure is capable of exhibiting independent numerical increase or decrease without metamorphosis. Where metamorphosis does occur it is the exception rather than the rule. It is in conformity with this that the total number of parts in the flower as a whole exhibits a wide range of variation, viz. from thirty to seventy-one.

It will also be seen from the data given that in general there is a marked tendency for all the whorls of the flower to exhibit trimery at the same time.

\section{(d) Transition.}

We have already noted the variability in form of the bracts, and that, though usually deeply divided, they always exhibit three main lobes which may be quite entire (cf. Fig. 9). Rarely, as noted by Irmisch (loc. cit.), an additional bract may be present accompanying a normal perianth of six coloured members-doubtless the result of bifurcation. In nearly all cases, however, where there is an additional bract it is found to consist of three entire lobes and to occupy the position of one of the outer perianth segments. An instructive example is represented in the diagram (Fig. 6, B). In this

1 The author has been unable to obtain a copy of the paper by Mori (Firenze, I910) on the correlative variation in this species. 
instance one member of the outer whorl had become transformed into a trilobed bract (Fig. 5, C) and the other two members of the whorl were undivided but exhibited a yellow central region and a green margin (Fig. 5, D). One or more members of the perianth may be trilobed and only partially virescent (Fig. 5, A). More rarely the trilobed structures are uniformly yellow (Fig. 5, B). Very rarely, too, one or more members of the involucre of bracts may exhibit partial petaloidy (Fig. 5, H). Such variations are too frequent to be regarded as mere abnormalities, for not only have they been observed in every locality from which material was obtained by the present writer, but they were recorded by Irmisch in 1860 as of frequent occurrence in the following passage: 'Nicht selten wird ein Hüllblatt mehr oder weniger vollständig in ein gelbes Kelchblatt verwandelt, oder es ist ein Kelchblatt zur Hälfte grün, zur anderen Hälfte gelb, oder einzelne Kelchblätter erscheinen, ohne die gelbe Farbe aufzugeben, nach Art der Hüllblätter mit tiefen Einschnitten,

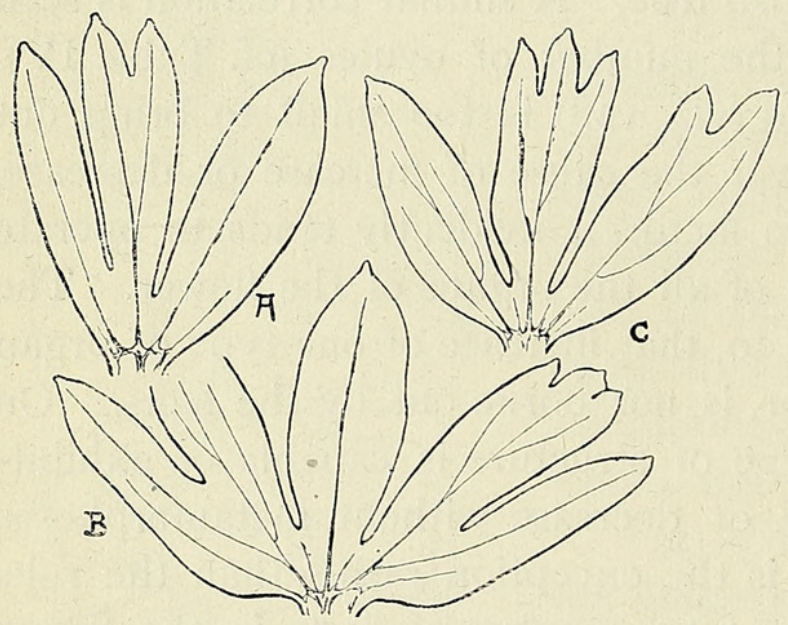

FIG. 9. Eranthis hyemalis. Variation in bracts. lauter Beweise für die innige Beziehung dieser Blattkreise $\mathrm{zu}$ einander' (1860, p. 225).

There have thus been observed almost every possible transition between the involucral bracts and the perianth members. Moreover the latter may be replaced by the former. That such phenomena repeatedly exhibited by healthy plants have some significance can scarcely be denied, and one can therefore only conclude that either the perianth members are petaloid bracts and that both had their origin in foliar structures, or that the bracts are derivatives of the perianth members and that both had their origin from sporophylls.

That the former view is the correct one is indicated on general grounds that will be considered later, but in this particular species we may note that the replacement of perianth members by bracts is not infrequent, whilst petaloid bracts are rare, and, as is well known, atavistic variations are usually much commoner than those of a progressive character.

Moreover, the vascular supply of the perianth member corresponds closely with that of the bract, whilst even petaloid nectaries when well developed do not show the same vascular organization. It is, however, true that the supernumerary petals do help to bridge this gap.

The most important argument is undoubtedly that in no case have we found a perianth member replaced by a nectary or showing any signs of transition to one. Thus if we were to accept the other alternative we 
should have the unique condition of a whorl which exhibited variations exclusively in the direction of progression.

In a few flowers nectaries have been observed one side of which bore an anther containing apparently fertile pollen (Fig. 2, G and H, $\alpha$ ). These and the rare instances of two nectaries on the same staminal orthostichy show that here, as is probably the case for all the Helleboreae, the nectaries are staminodal structures. That is to say, the honey-leaves bearing anthers are to be regarded as reversions.

Not infrequently nectaries showing an enlarged petaloid anterior lobe are encountered (Fig. 2, F), thus emphasizing the potentialities of the androecium in this direction. Such petaloid nectaries are always situated on the staminal orthostichies and in this respect differ from the supernumerary perianth segments. Moreover they usually exhibit only one vascular bundle at the base and, in all the cases seen, show some indication of a nectary. An interesting example is illustrated in Fig. 2, E, where the resemblance to the staminodal petal of Ramunculus is striking. But this condition, whilst indicating how the adaxial scale of that genus may have arisen, is too rare to be regarded as an indication of any tendency here.

\section{TABLE I.}

\section{Evanthis hyemalis.}

Number of

Nectaries.

$\begin{array}{rrr}4 & \text { Number of specimens } \\ 5 & , & , \\ 6 & , & , \\ 7 & , & , \\ 8 & , \\ 9 & , & , \\ \text { I0 } & , \\ \text { I I } & , \\ \text { I 2 } & ,\end{array}$

Totals .
Number of Perianth Segments.

Totals.

$$
5
$$

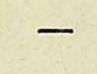

$6.6 \%$

$$
6
$$

$100 \%$
$9 \%$

$\begin{array}{rr}6.6 \% & 59.9 \\ - & 163 \\ & 92\end{array}$

I 50

$1.5 \%$

$4 \cdot 1 \%$

$76.5 \%$

$66.6 \%$

$44.4 \%$

$\begin{array}{r}46.6 \% \\ \hline\end{array}$

$-$

$-$

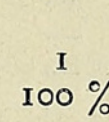

3
I $\% \quad 82.6 \%$

33
II $\%$
7

8

\begin{tabular}{|c|c|c|}
\hline- & - & - \\
\hline $26.6 \%$ & I $6.6 \%$ & - \\
\hline $\begin{array}{l}12 \\
6.7 \%\end{array}$ & $\begin{array}{r}2 \\
\mathrm{I} \cdot \mathrm{I} \%\end{array}$ & - \\
\hline $\begin{array}{c}6 \\
9.2 \%\end{array}$ & $\begin{array}{r}7 \\
10.7 \%\end{array}$ & $\begin{array}{c}\text { I } \\
\text { I.5 \% }\end{array}$ \\
\hline $\begin{array}{r}5 \\
20.8 \%\end{array}$ & $8.3 \%$ & - \\
\hline $\begin{array}{r}3 \\
33 \cdot 3 \%\end{array}$ & $\begin{array}{r}2 \\
22.2\end{array}$ & - \\
\hline $16.6 \%$ & I $6.6 \%$ & - \\
\hline & - & - \\
\hline
\end{tabular}

9 
Number of

TABLE II.

Evanthis hyemalis.

Stamens.

Number of Nectaries.

Totals.

18
19
20
21
22
23
24
25
26
27
28
29
30
31
32
33
34
35
36
37
38
39
40
41
42
43
44

Number of

Stamens.

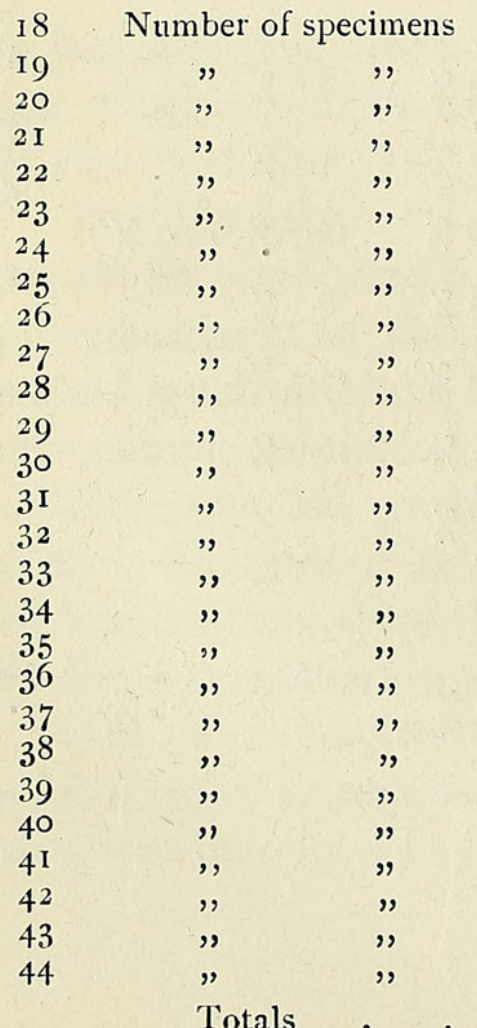

$\begin{array}{lllllllll}4 & 5 & 6 & 7 & 8 & 9 & \text { IO } & \text { II } & \text { I } 2\end{array}$

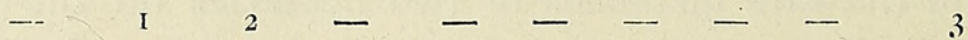

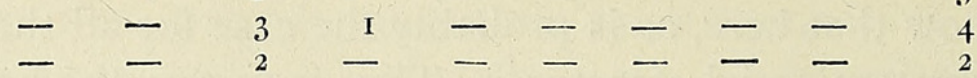

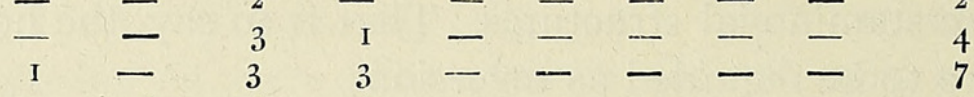

$$
\begin{aligned}
& \begin{array}{llll} 
& 1 & 5 & 3
\end{array}-0-19 \\
& \begin{array}{lllllllll}
2 & 25 & 2 & 1 & - & - & 3^{1}
\end{array}
\end{aligned}
$$

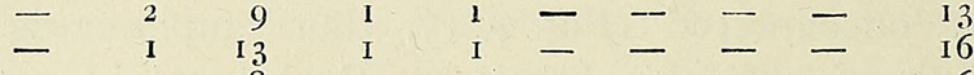

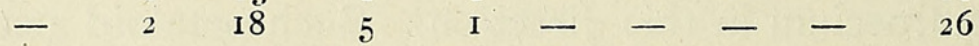

$$
\begin{aligned}
& \text { - } 210 \quad 5-13
\end{aligned}
$$

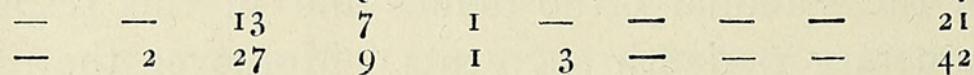

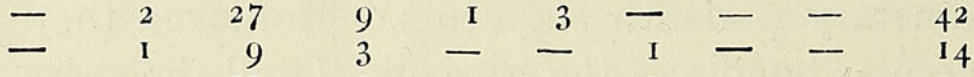

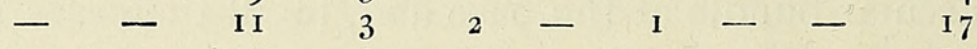

$$
\begin{aligned}
& \text { - }-93 \quad 3-\begin{array}{lll}
1 & 9 & 3
\end{array} \\
& \text { - }-\frac{2}{6} \quad \begin{array}{llllll}
4 & 1 & - & - & - & -
\end{array} \\
& \text { - }-\begin{array}{rrrrr}
6 & 4 & 2 & - & -
\end{array} \\
& \text { - }-\begin{array}{llll}
4 & 4 & 2 & \\
\hline & 1 & 2 & -
\end{array}
\end{aligned}
$$

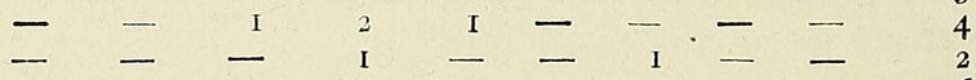

$$
\begin{aligned}
& \begin{array}{l}
- \\
-
\end{array}
\end{aligned}
$$

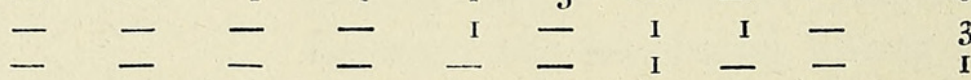

$$
\begin{aligned}
& \text { - }-\quad-\quad-\quad \begin{array}{llllll}
1 & - & - & - & -
\end{array}
\end{aligned}
$$

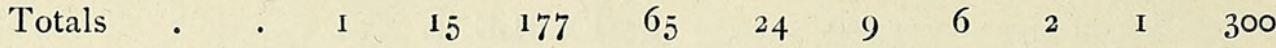

$$
\begin{aligned}
& \text { TABLE III. }
\end{aligned}
$$

Eranthis hyemalis.

Number of Carpels.

Totals.

$$
\begin{aligned}
& \begin{array}{llllllll}
3 & 4 & 5 & 6 & 7 & 8 & 9 & \text { I0 }
\end{array} \\
& 3 \text { - I - - - - - } 3
\end{aligned}
$$

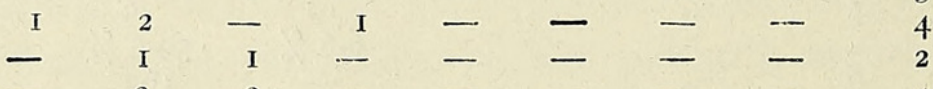

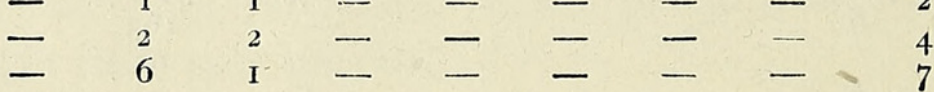

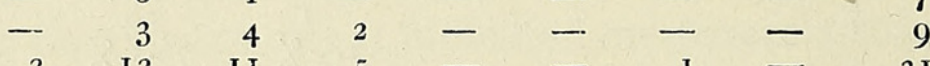

$$
\begin{aligned}
& \begin{array}{llllllll}
2 & \text { I } & \text { II } & 5 & - & - & 1 & -
\end{array} \\
& \begin{array}{llllll}
1 & 3 & 8 & 1 & - & -
\end{array}
\end{aligned}
$$

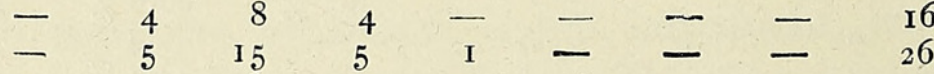

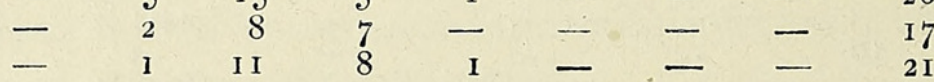

$$
\begin{aligned}
& \text { - } 2 \text { I3 }^{24} 3 \text { - } \quad \text { - }-4^{2}
\end{aligned}
$$

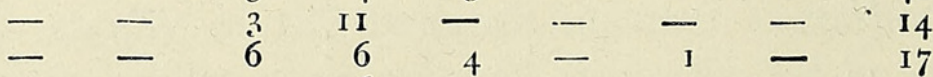

$$
\begin{aligned}
& \text { - }=5 \begin{array}{lllll} 
& 5 & 6 & \text { I } & -
\end{array}
\end{aligned}
$$

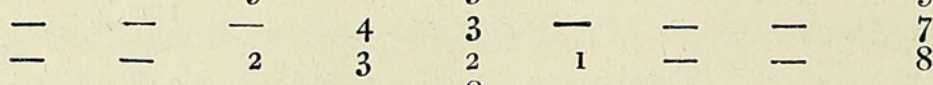

$$
\begin{aligned}
& \text { - }-\quad-\quad 4 \quad 8-I_{-} \text {I } \\
& \text { - }-\begin{array}{llllll} 
& 1 & 3 & 2 & 2 & -
\end{array} \\
& \text { 二 - }- \text { - }-3 \quad \begin{array}{lllll}
2 & - & 2 & - & 5 \\
\hline
\end{array}
\end{aligned}
$$

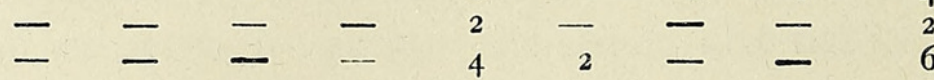

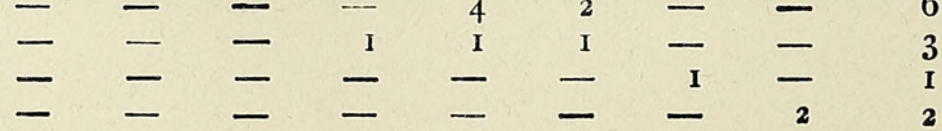

$$
\begin{aligned}
& \begin{array}{lllllllll}
6 & 43 & 100 & 95 & 39 & 7 & 7 & 3 & 300
\end{array}
\end{aligned}
$$


Ficaria verna, and other Members of the Ranunculaceae. $6 \mathrm{I}$

TABLE IV.

Eranthis hyemalis.

Number of

Carpels in

Flower.

$\begin{array}{lll}4 & \text { Number of specimens } \\ 5 & " \\ 6 & ", \\ 7 & , & " \\ 8 & , & , \\ 9 & , & ,\end{array}$

Totals

\section{Number of Ovules.}

\begin{tabular}{|c|c|c|c|c|}
\hline 6 & 7 & 8 & 9 & IO \\
\hline- & $\begin{array}{c}8 \\
66.6\end{array}$ & $33.3^{4} \%$ & - & - \\
\hline $\begin{array}{r}5 \\
25\end{array}$ & $\begin{array}{r}8 \\
40 \%\end{array}$ & $\begin{array}{r}335 \% \\
60 \% \\
30 \%\end{array}$ & - & \\
\hline $\begin{array}{r}5 \\
\text { I1. }\end{array}$ & $\begin{array}{r}11 \\
26.1 \%\end{array}$ & $\begin{array}{r}18 \% \\
42.8 \%\end{array}$ & $\stackrel{5}{\text { I I. } 0 \%}$ & $\begin{array}{r}5 \\
3 \\
7.2\end{array}$ \\
\hline & & $\begin{array}{l}11 \\
55 \%\end{array}$ & & $\begin{array}{l}\text { I } \\
5\end{array}$ \\
\hline${ }^{2} .5 \%$ & $\begin{array}{c}4 \\
25\end{array}$ & ${ }_{25}^{4} \%$ & $\begin{array}{r}6 \\
36.5 \%\end{array}$ & - \\
\hline $5.5 \%$ & $33.3 \%$ & $44.4 \%$ & II \% & 5.5 \\
\hline I3 & 43 & $5 \mathrm{I}$ & ${ }^{\prime} 5$ & 6 \\
\hline
\end{tabular}

I 28

\section{Ficaria verna, L.}

The flower of this species (cf. Clos, 1852 ; Baillon, 1863, p. 4 ; Payer, 1857 , p. 254) usually consists of a calyx of three members, exhibiting a one-third spiral, followed by eight or seven coloured perianth segments bearing nectaries. The androecium is most commonly composed of from eighteen to twenty-five stamens which show an obvious tendency to dehisce in whorls of three, though the successive whorls exhibit lateral displacement (cf. Fig. IO, G-H). The gynaeceum generally consists of from nine to twenty-four carpels, the lower numbers being often clearly arranged in trimerous whorls.

\section{(a) Meristic variation.}

(I) The calyx. The number of sepals ranges from three to seven, more than 400 of the $5^{1} 4$ examples examined possessing the former number. The arrangement of the extra sepals as shown in Fig. $\mathrm{IO}, \mathrm{A}-\mathrm{H}$, negatives any suggestion that these are transformed petals. It is true that the sepals are sometimes coloured, but in no instance do such bear any indication of a nectary, which is always present on virescent petals. On the other hand, the position of the supernumerary sepals $\left(\mathrm{K}_{1}{ }^{\prime}-\mathrm{K}_{3}{ }^{\prime}\right)$ does harmonize with the view that they represent fission products of one or more of the three members normally present $\left(\mathrm{KI}-\mathrm{K}_{3}\right)$. We thus have exhibited in the calyx a phenomenon commonly met with in other members of the group and also in the other whorls of this flower. Celakovsky's dogmatic statement that these extra sepals here, and in Anemone hepatica, are modified members of the coloured perianth within cannot therefore be upheld. Having regard to the correlation generally exhibited between the number of parts in the different whorls, it might be regarded as strong evidence against the view 
here expressed that high calyx numbers are frequently associated with a low. perianth number. But the examples given (cf. Fig. 10, G and H) show that the absent petal in each case is a member of the inner whorl and not of the outer. Hence one cannot be dealing with an instance of transformation. The underlying cause is doubtless nutrition. The sepals being large in number

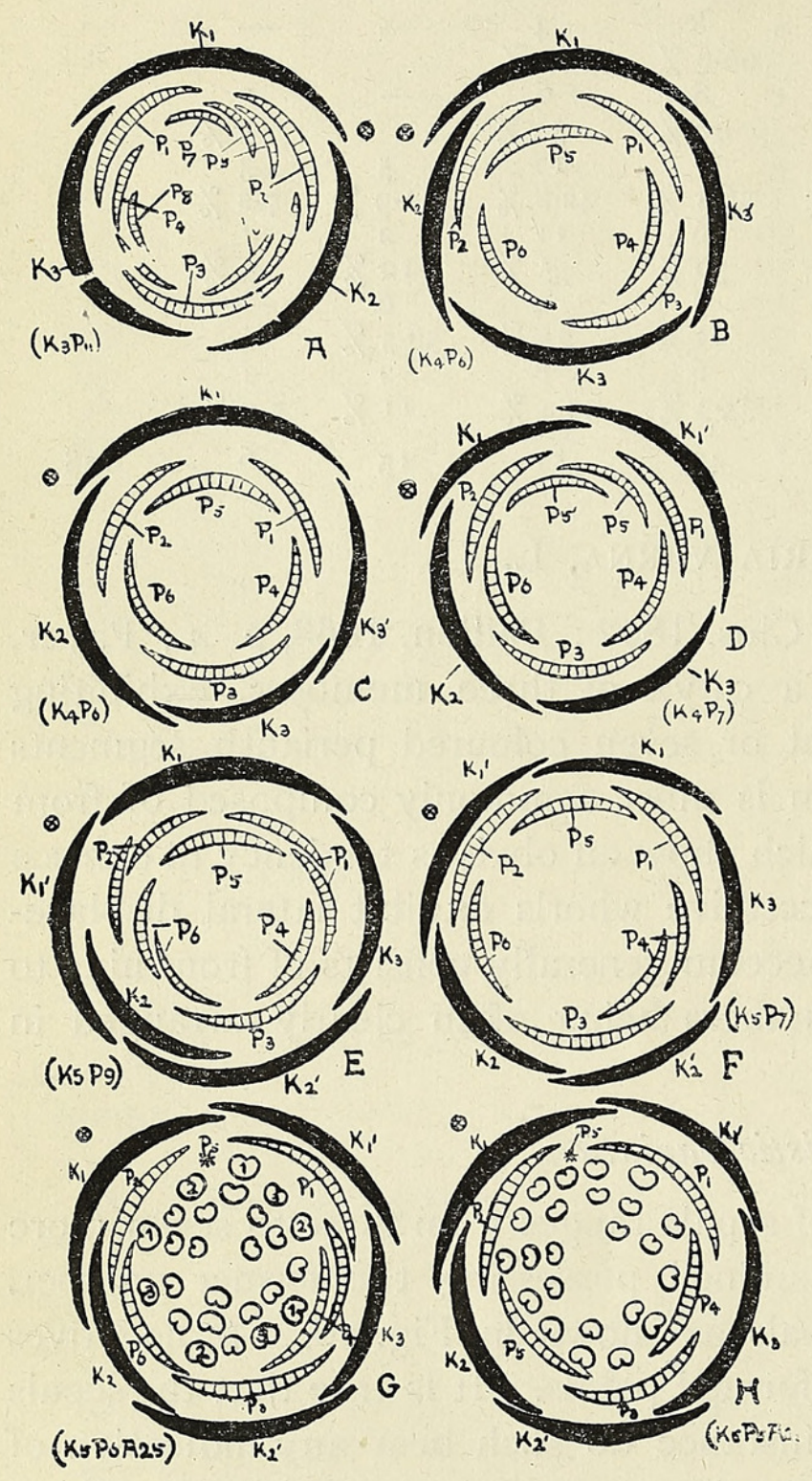

FIG. 10. Ficaria verna. Empirical diagrams showing arrangement of the perianth segments and stamens. The numbers indicate the order of dehiscence. $\mathrm{KI}^{\prime}-\mathrm{K}^{\prime}$ indicate fission products of the calyx-segments normally present $(\mathrm{K} \mathrm{I}-\mathrm{K} 3)$. and the first parts of the flower to develop, have entailed a drain upon the nutrition which is met by an absence of fission in the corolla, or even, as in these cases, a suppression of one member.

(2) The corolla. The number of petals ranges from four to eleven, although eight is much the most frequent. A study of the diagrams (Fig. Io) of several of the more conspicuous variants, as also of quite normal flowers, shows that the multifarious types presented are all explicable on the assumption that the corolla is typically trimerous, but that two members of the inner whorl, and sometimes all three, exhibit fission into two separate segments. The numbering of the petals in the diagrams is based on this assumption. More rarely the outer corolla whorl also exhibits fission (cf. PI, P2, Fig. IO, E). Eichler regarded these supernumerary members in both Ficaria verna and Anemone hepatica as independent additional members, but in the latter species admits the occurrence of more or less fused members (Eichler, 1875, Bd. I, p. $\left.15^{8}\right)$. Such cases of partial fission (cf. Fig. I I, G) have been observed by the writer in several specimens, and their position fully warrants the assumption that they represent two members which in the more common condition are distinct. Very rarely additional nectary-bearing petals are present which must, from their position with regard to the staminal orthostichies and the other perianth 
Ficaria verna, and other Members of the Ranunculaceae. 63

members, be interpreted as transformed stamens. It is important to recognize this fact that even here, where the corolla segments have obviously originated from stamens (as have the honey-leaves in other Ranunculaceae), increase in number is far more frequently an outcome of the fission of the rudiments already present than of further transformation of stamens. Hence we find a correlated increase in the androecium and corolla. In the example instanced, however, in which the position of the supernumerary petals indicated transformation, the correlated increase of the androecium was much less pronounced than the normal.

(3) The androecium. The variation 'curve' for this region of the flower exhibits the same salient features as in Eranthis hyemalis. Out of a total

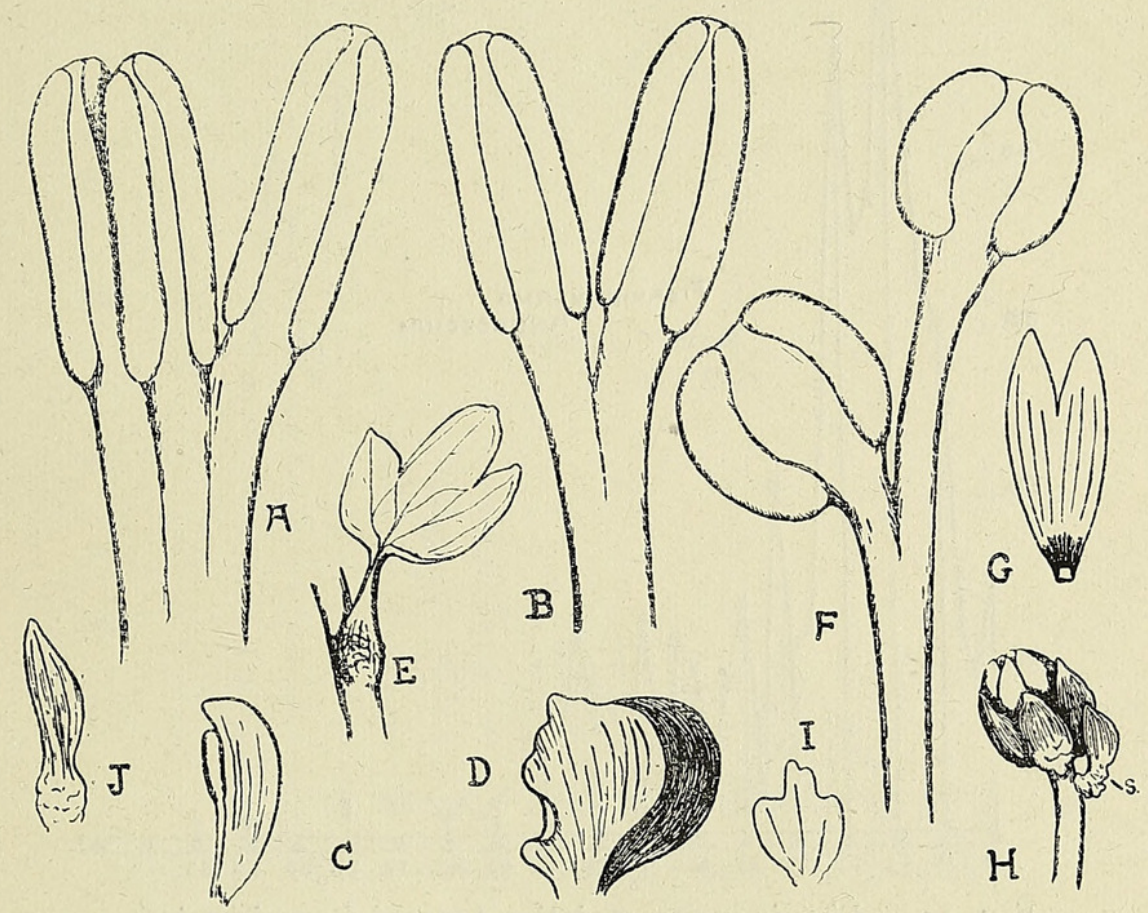

FIG. II. A and B, branched stamens of Ficaria verna; C, petaloid stamen; D, partially coloured sepal; E, sepal with lobed lamina; F, Anemone nemorosa, branched stamen; G, bilobed petal of Ficaria verna; H-J, variation in the sepals of $F$. verna.

of over 500 flowers completely dissected the minimum number of stamens exhibited by any flower was a multiple of three. This minimal condition should, if the variation 'curve' were of the normal type, be only presented by a very small percentage of individuals. In actual fact there were no less than fifteen examples, a number so high as not merely to emphasize the reality of this secondary maximum, but also the abrupt character of the lower limit.

It is also very significant that the three highest numbers observed were also multiples of the three and occur as isolated points on the variation 'curve', since the largest number, not a multiple of three, was forty-nine (cf. Fig. 12).

Most frequently the androecium consists of either twenty-one or twenty-four stamens, but secondary maxima also occur at most other 
multiples of three, the only notable exception being the number twentyseven, of which there were only eleven examples ; but this is doubtless correlated with the large number of flowers exhibiting twenty-eight stamens (viz. twenty-one), many of which are probably the outcome of complete fission of one of the staminal rudiments. Hence we get an increase of the higher category at the expense of the lower.

We thus have again a 'curve' which may be regarded as consisting of a number of secondary variation 'curves', each having some multiple of three as its mode. Departure from the mode is to be interpreted as an outcome

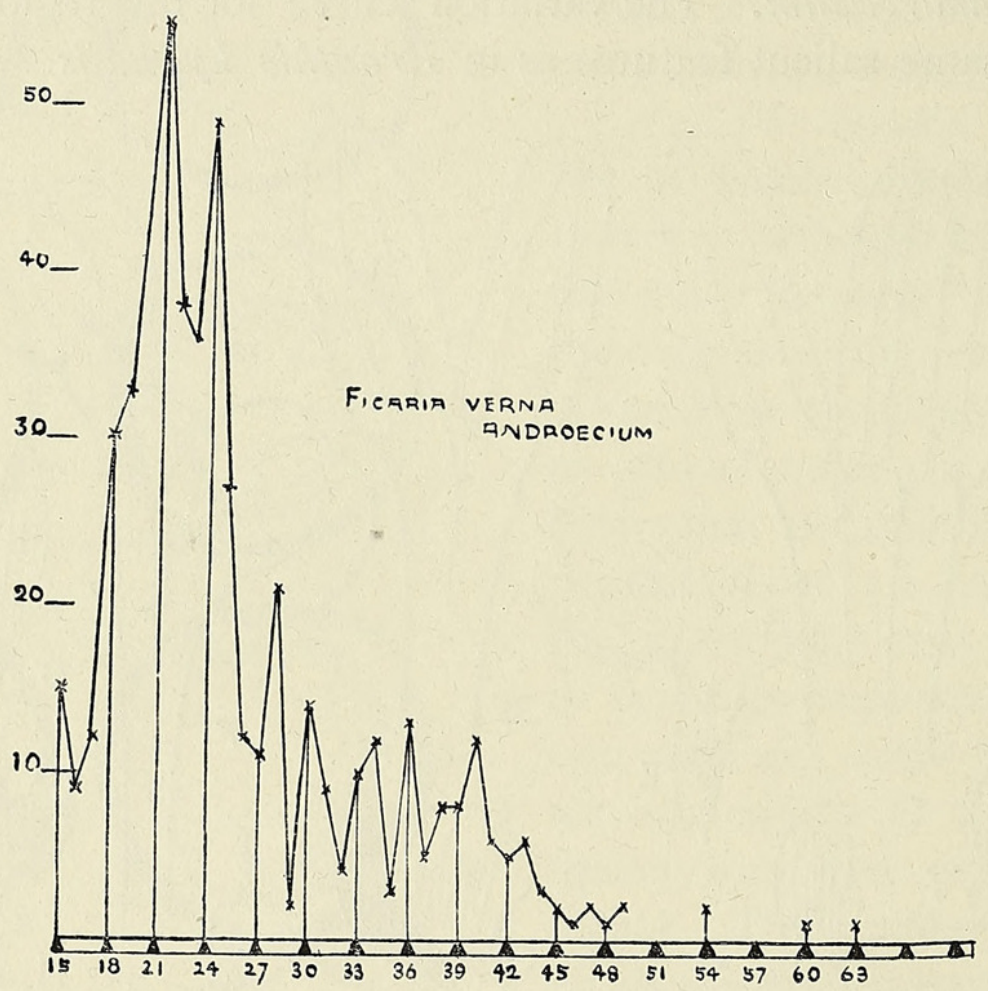

FIG. I 2. Ficaria verna, variation 'curve' for androecium.

of fission or of fusion. Here, as in Evanthis, branched stamens are not infrequent, and examples are figured in which two or even three anthers occur on the same filament (Fig. II, A and B). Rarely small abortive stamens have been observed, so that complete suppression may sometimes have taken place.

(4) The gynaeceum. Here again, although the feature is less marked (cf. Fig. I3), the maxima on the variation 'curve' are chiefly situated at multiples of three, the most frequent number being I 5 . The general trend exhibits the same markedly asymmetrical form so frequently characterizing that of the perianth.

\section{(b) Correlation.}

Tables V and VI bring out the fact that there is a marked correlation between the different whorls as regards either increase or decrease, so that we cannot attribute an augmented corolla to staminal transformation, 
Ficaria verna, and other Members of the Ramunculaceae. 65

except in special cases, as that instanced above. In illustration we find that of the seven examples with eleven petals only one has twenty-four stamens, whilst the remaining six have from thirty-eight to sixty-three. Table $\mathrm{V}$ shows that twenty per cent. of the flowers have stamens and carpels which at the same time number some multiple of three.

\section{(c) Transition.}

Partially transformed stamens have been sometimes encountered, and one instance is here figured (Fig. I I, C). These emphasize the staminodal character of the petals.

By far the commonest substantive variation is that found in the calyx,

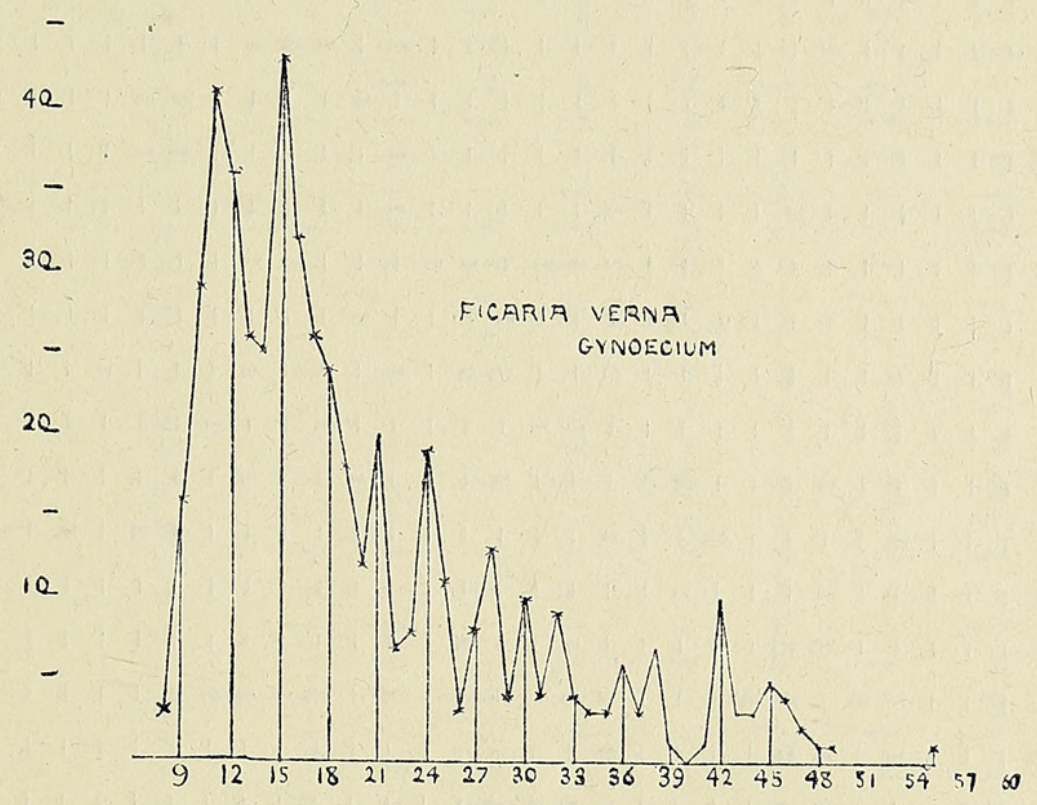

FIG. I3. Ficaria verna, variation 'curve' for gynaeceum.

where one or more members become more or less leafy (Fig. I I, H-J) and develop a blade that is often lobed (Fig. I I, E). There seems little doubt, from a study of all the transition stages, that the sepals really represent the basal region of modified bracts. It is also significant that where complete reversion takes place it is to the lobed, probably primitive, type of leaf, and not to the specialized simpler form of the foliage proper. Examples such as these afford the strongest evidence that the sepals had their immediate origin from foliar structures and not from sporophylls, as on the latter assumption the lobed form is inexplicable.

A partially coloured sepal is shown in Fig. II, D, but, as has already been pointed out, such cases can invariably be distinguished from true petals. The fact that the sepals can become coloured is well exemplified in many Ranunculaceae, and merely illustrates the possibility of an attractive whorl being developed from either source of origin. 


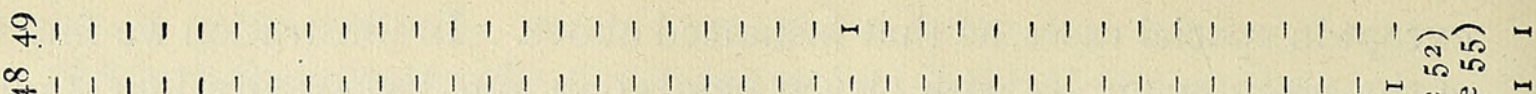

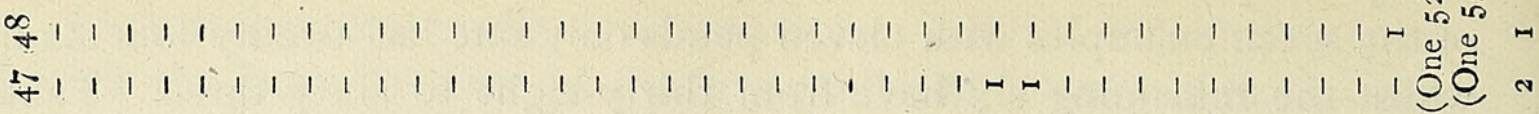

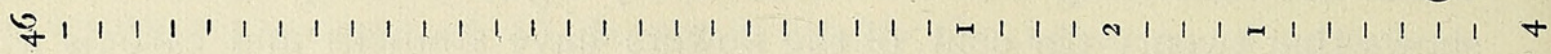

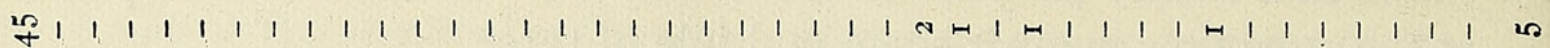

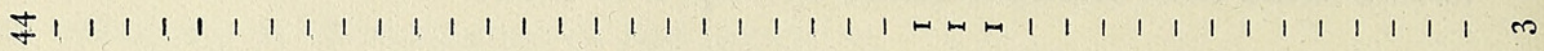

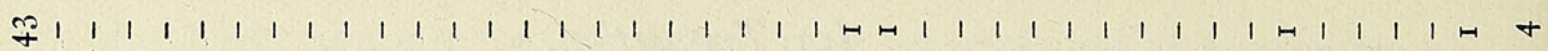
$\begin{array}{lllllllllllllllllllllllllllllllllllllllllll}7 & 1 & 1 & 1 & 1 & 1 & 1 & 1 & 1 & 1 & 1 & 1 & 1 & 1 & 1 & 1 & 1 & 1 & 1 & 1 & 1 & 1 & 0 & 1 & H & 1 & N & 1 & 1 & 1 & 1 & -1 & 1 & 1 & 1 & 1 & 1 & 1 & 1 & 1 & 1 & 9\end{array}$

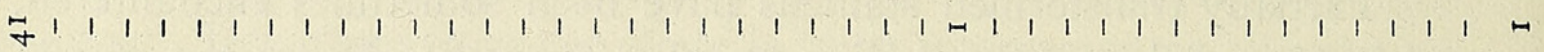

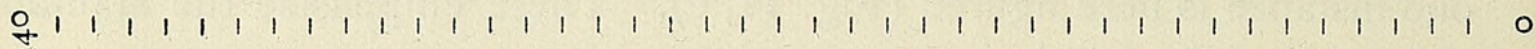

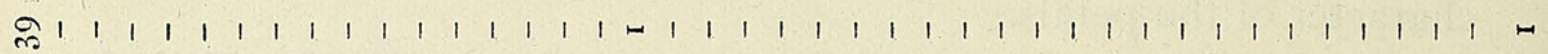

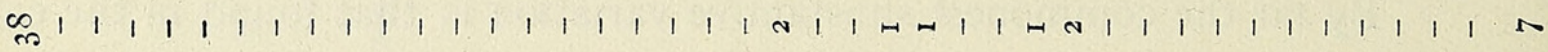

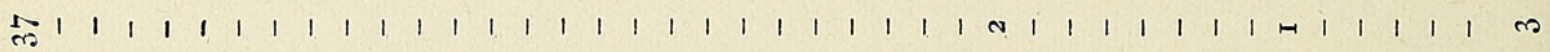

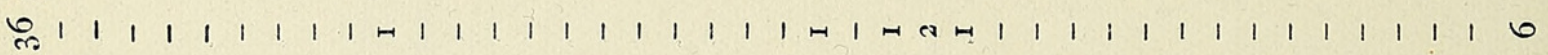

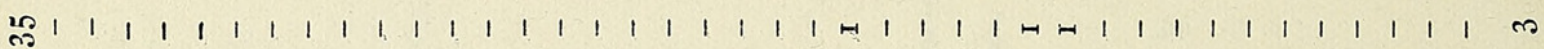

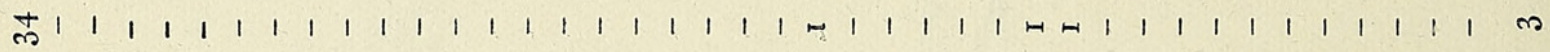

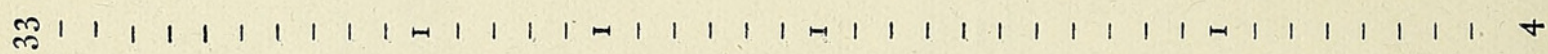
今

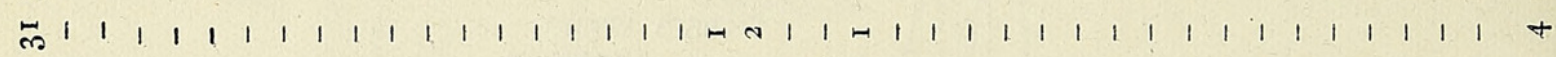

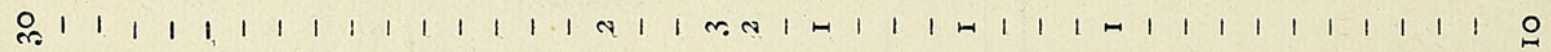

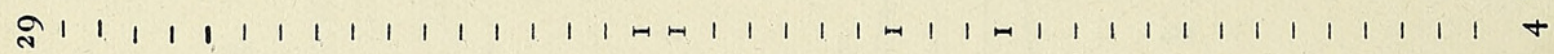

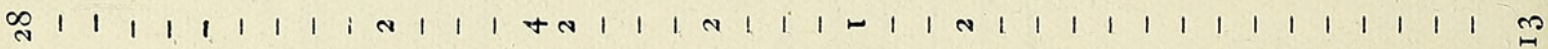

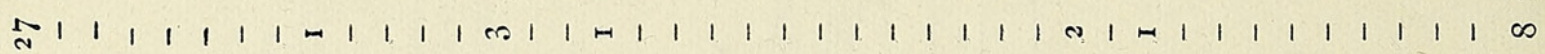
$\begin{array}{lllllllllllllllllllllllllllllllllllllllllll} & 1 & 1 & 1 & 1 & 1 & 1 & 1 & 1 & 1 & -1 & 1 & 1 & 1 & 0 & 1 & 1 & 1 & 1 & 1 & 1 & 1 & 1 & 1 & 1 & 1 & 1 & 1 & 1 & 1 & 1 & 1 & 1 & 1 & 1 & 1 & 1 & 1 & 1 & 1 & 1 & 0\end{array}$

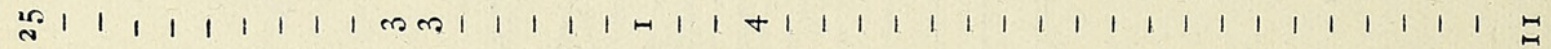
से 1 |

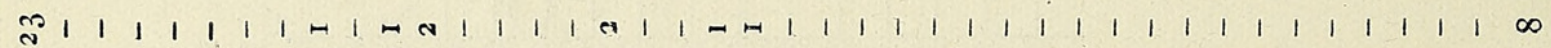

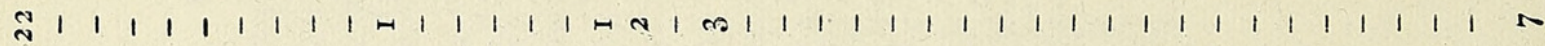

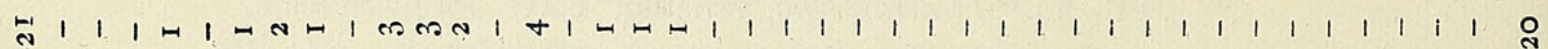
$\begin{array}{llllllllllllllllllllllllllllllllllllllllllll}0 & 1 & 0 & 1 & n & 1 & 1 & 1 & 1 & 2 & 1 & 1 & 0 & n & 1 & 1 & 1 & 1 & 1 & 1 & 1 & 1 & 1 & 1 & 1 & 1 & 1 & 1 & 1 & 1 & 1 & 1 & 1 & 1 & 1 & 1 & 1 & 1 & 1 & 1 & n\end{array}$

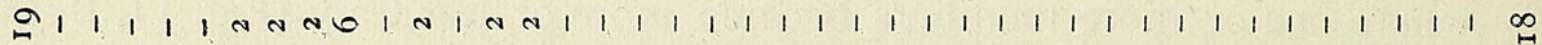

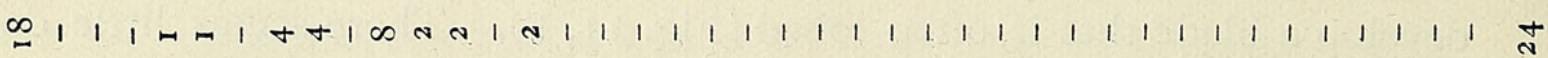

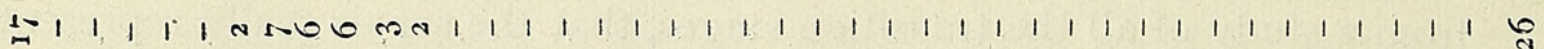

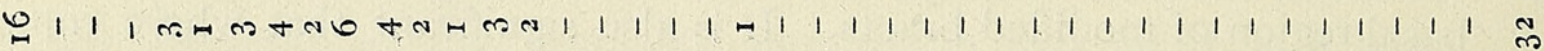
m 1 1 1 m m 1 o Am 政H in \#DNGHN 연

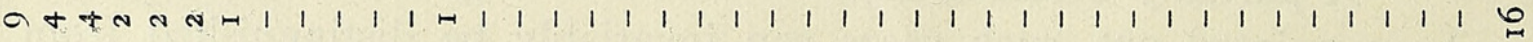

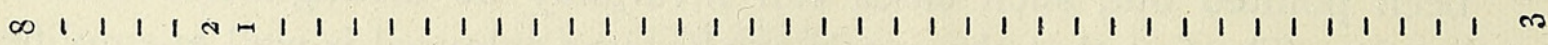

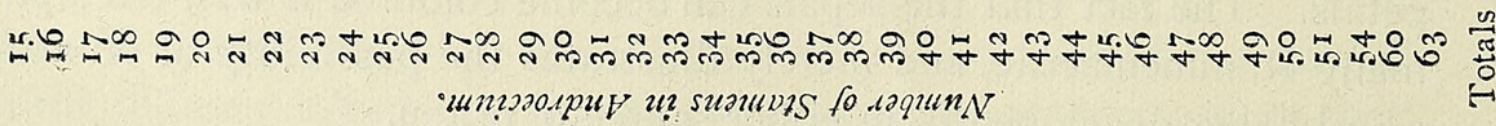




\section{TAble Vi. VARIATION of Corolla and ANDroecium in} FICARIA VERNA. 5I4 flowers.

Number of

Stamens.

\begin{tabular}{|c|c|c|c|c|c|c|c|c|c|c|c|}
\hline & & 4 & 5 & 6 & 7 & 8 & 9 & Io & II & 12 & \\
\hline I 5 & Number of specimens & - & - & 2 & 5 & 8 & - & - & - & - & 15 \\
\hline 16 & $"$, & - & - & 3 & I & 5 & - & - & - & - & 9 \\
\hline 17 & ," & - & 2 & 4 & 6 & $\div$ & - & - & -. & - & I 2 \\
\hline 18 & ," & - & I & 9 & 2 & I 8 & 一 & - & - & - & 30 \\
\hline I9 & " & - & - & 4 & 16 & It & - & - & - & - & 34 \\
\hline 20 & $"$ & - & I & 3 & 8 & I 4 & - & - & - & - & 26 \\
\hline $2 \mathrm{I}$ & $"$ & I & I & 14 & I 7 & 23 & 一 & - & - & - & 56 \\
\hline 22 & $"$ & - & 3 & 2 & 9 & I9 & 5 & - & - & - & $3^{8}$ \\
\hline 23 & $"$ & - & I & 7 & II & I 7 & - & I & - & - & 37 \\
\hline 24 & $"$ & I & - & 4 & ז6. & 24 & 3 & - & I & - & 49 \\
\hline 25 & $"$ & - & - & 6 & 4 & I 6 & I & - & - & - & 27 \\
\hline 26 & $"$ & - & - & - & 4 & 7 & I & - & - & - & 12 \\
\hline 27 & $"$ & - & - & I & - & 9 & I & - & - & - & II \\
\hline 28 & $"$ & - & - & 2 & 5 & 14 & - & - & - & - & $2 I$ \\
\hline 29 & $"$ & - & - & - & - & 2 & - & - & - & - & 2 \\
\hline 30 & $"$ & - & - & - & 2 & 8 & 3 & - & - & - & 13 \\
\hline $3 \mathrm{I}$ & $\Rightarrow "$ & - & - & - & - & 7 & 3 & - & - & - & 10 \\
\hline $3^{2}$ & " & - & - & - & - & 7 & - & - & - & - & 7 \\
\hline 33 & $"$ & - & - & - & - & 10 & I & - & - & - & I I \\
\hline 34 & $"$ & - & - & - & - & IO & 2 & - & - & - & 12 \\
\hline 35 & " & - & - & - & - & 2 & I & - & - & - & 3 \\
\hline 30 & ", & - & - & - & $\cdots$ & 7 & 2 & I & - & - & IO \\
\hline 37 & " & - & - & - & - & I & 2 & 3 & - & - & 6 \\
\hline $3^{8}$ & ", & - & - & - & - & 2 & 4 & I & I & - & 8 \\
\hline 39 & 2 & - & - & - & - & 6 & 2 & 2 & 3 & - & I3 \\
\hline $4^{\circ}$ & $"$ & - & - & - & - & 4 & I & 2 & - & - & 7 \\
\hline $4 \mathrm{I}$ & , & - & - & - & - & 2 & 3 & 2 & - & - & 7 \\
\hline 42 & $"$ & - & - & - & - & - & 3 & 3 & - & - & 6 \\
\hline 43 & , & - & - & - & - & 4 & I & I & - & - & 6 \\
\hline 44 & $"$ & - & - & - & - & - & 2 & - & I & - & 3 \\
\hline 45 & " & - & - & - & - & 2 & - & - & - & - & 2 \\
\hline $4^{6}$ & ", & - & - & - & - & 2 & - & - & - & - & 2 \\
\hline 47 & , & - & 一 & - & I & I & - & I & - & - & 3 \\
\hline $4^{8}$ & " & - & - & - & $\ldots$ & - & 2 & - & - & - & 2 \\
\hline 49 & , & 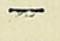 & - & - & - & - & - & - & - & - & - \\
\hline 50 & $"$ & - & Z & - & - & - & - & 一 & - & - & - \\
\hline 54 & ", & - & - & - & - & $\longrightarrow$ & I & - & - & - & I \\
\hline & , & - & - & - & - & - & - & I & - & - & I \\
\hline 63 & ", & - & - & - & - & - & 1 & - & I & - & 2 \\
\hline & Totals & 2 & 9 & 6.1 & 107 & $2 \sigma_{5}$ & 45 & 18 & 7 & 0 & 514 \\
\hline
\end{tabular}

\section{ANEMONE NEMOROSA, L.}

Of this species only 152 flowers were dissected, which in view of the large number of parts involved is too few to give good variation 'curves'. These, however, show clearly the tendency for maxima to occur at multiples of three (cf. Figs. I4 and I5), a feature that, owing to the small number of examples, is somewhat obscured by the overlap of the variations around the trimerous maxima. As is well known, the perianth here frequently consists of two whorls of three members each; when, however, a greater number are present the orientation of the supernumerary segments warrants the assump. tion that here again increase is the outcome of fission (Fig. I6, A). Where, however, the number is fewer (e.g. five) the insertion suggests fusion of one 
member of the outer whorl with one of the inner, in consequence of which a quincuncial arrangement results. The involucre in one case has been observed to exhibit increase, four bracts being present in place of the usual three, so that here too we have fission exemplified.

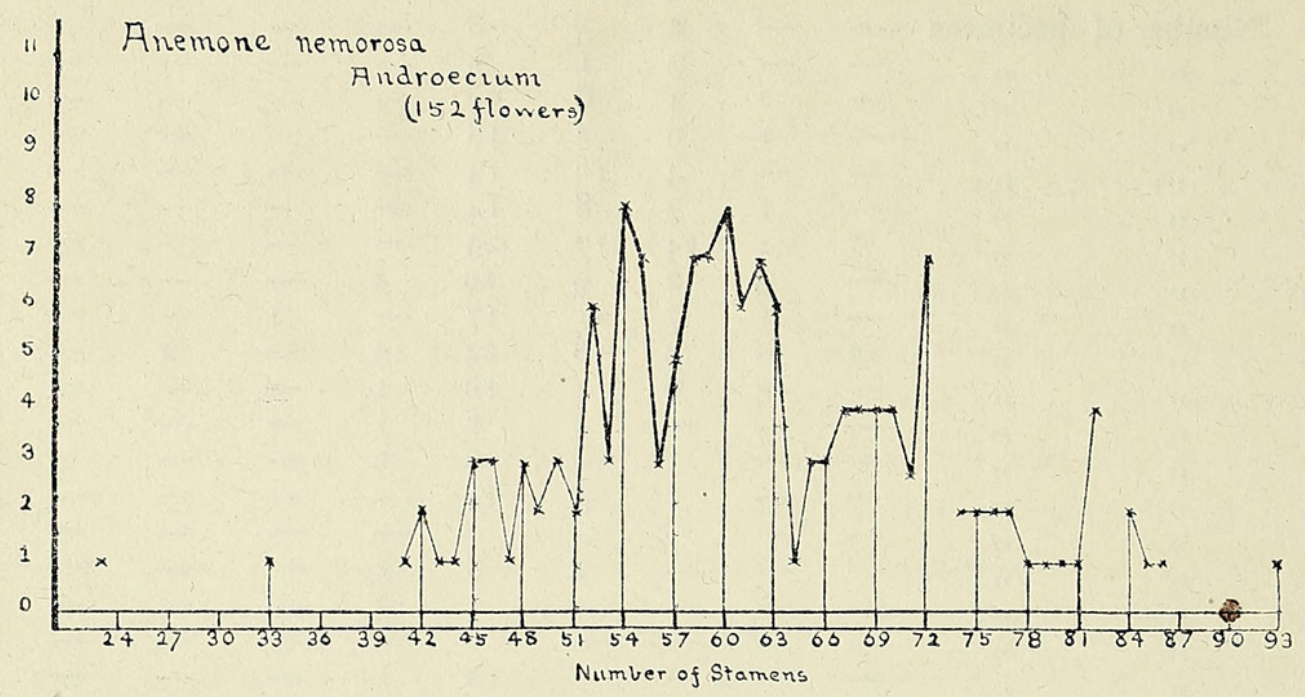

FIG. I4. Anemone nemorosa, variation 'curve' for androecium.

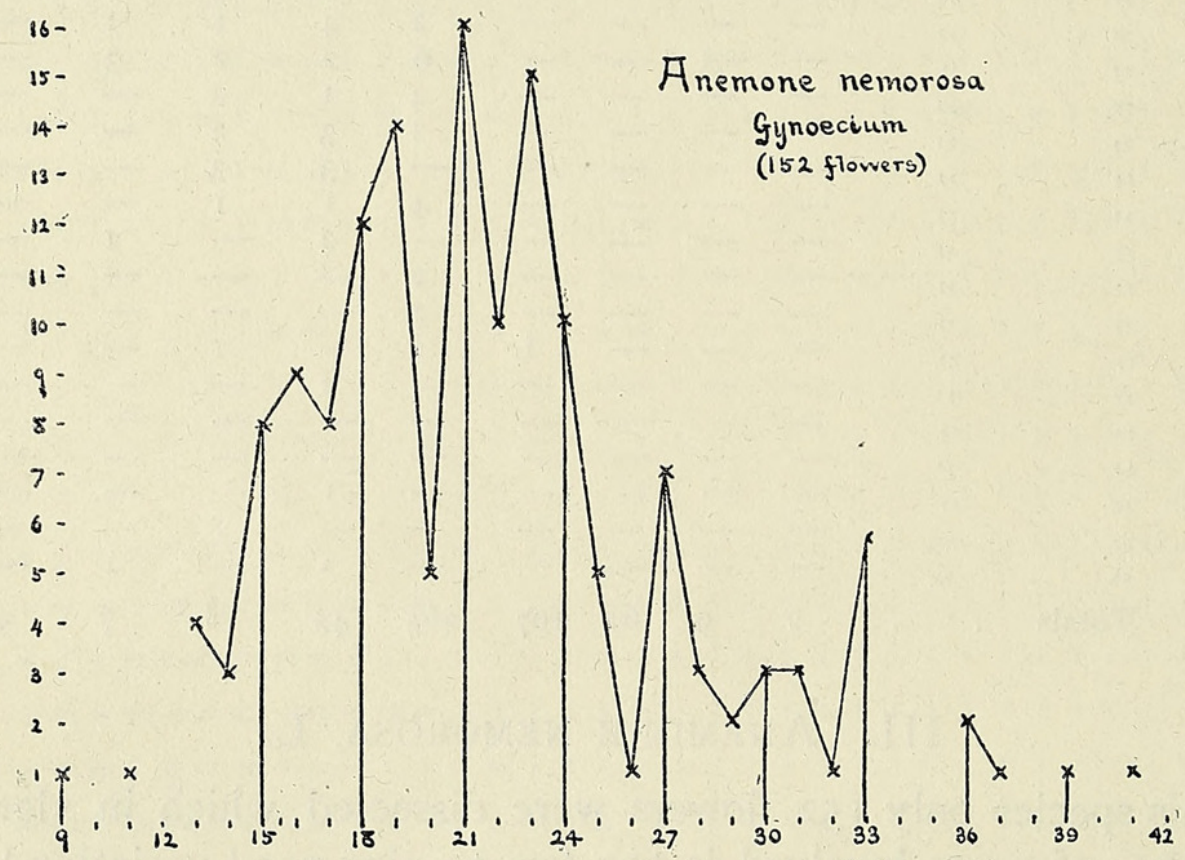

FIG. 15. Anemone nemorosa, variation 'curve' for gynaeceum.

As shown in Fig. I I, F, branched stamens occur, so that it would appear as if increase in the number of parts may take place in any whorl of the flower as a result of fission of rudiments already present. It will be noticed (Table VII) that, if we ignore the branching, four out of the six examples have androecia which are multiples of three.

Here too there is obvious correlation, for we find the coefficient between stamens and carpels is 0.66 , whilst the probable error is 0.03 . 
Between perianth segments and stamens the correlation coefficient is $0 \cdot 16$ and the probable error 0.055 . Complete or partial abortion of the male or female organs, accompanied by increase of those of the other sex, may occur in this and other species (cf. Elmore, 1915).

\section{TABLE VII.}

Anemone nemorosa.

\section{Number of Stamens.}

54
54
54
42
59
59

54

:
Number of

Branched Slamens.
Transitions are rare, but the sepals sometimes develop laminae, in which case the apical region is lobed and green, suggesting that here, as in Ficaria, the sepal merely represents the basal region of the bract or foliage leaf of which it is the derivative (cf. Baillon, 1863, p. 2, and Salisbury, 1916, p. 526, Fig. I).

In eleven flowers, or about 6.5 per cent. of the total, all the floral whorls consisted of some multiple of three, the details of which are given below (Table VIII).

\section{TABLE VIII.}

Anemone nemorosa.

$\begin{array}{cccc}\begin{array}{c}\text { Perianth } \\ \text { Segments. }\end{array} & \text { Stamens. } & \text { Carpels. } & \begin{array}{c}\text { Number of } \\ \text { Specimens. }\end{array} \\ 6 & 42 & \text { I5 } & \text { I } \\ 6 & 42 & \text { I } & \text { I } \\ 6 & 45 & 15 & \text { I } \\ 6 & 54 & \text { I5 } & 2 \\ 6 & 54 & 18 & \text { I } \\ 6 & 54 & 21 & \text { I } \\ 6 & 60 & 27 & \text { I } \\ 6 & 63 & 27 & 2 \\ 6 & 93 & 33 & \text { I }\end{array}$

As there were fifty-eight flowers with stamens numbering some multiple of three, the calculated probability is that about nineteen of these should possess carpels numbering some multiple of three; in actual fact there were no less than twenty-five such cases.

\section{Number of \\ Anthers.}

$$
\begin{aligned}
& 55 \\
& 55 \\
& 55 \\
& 44 \\
& 60 \\
& 61
\end{aligned}
$$

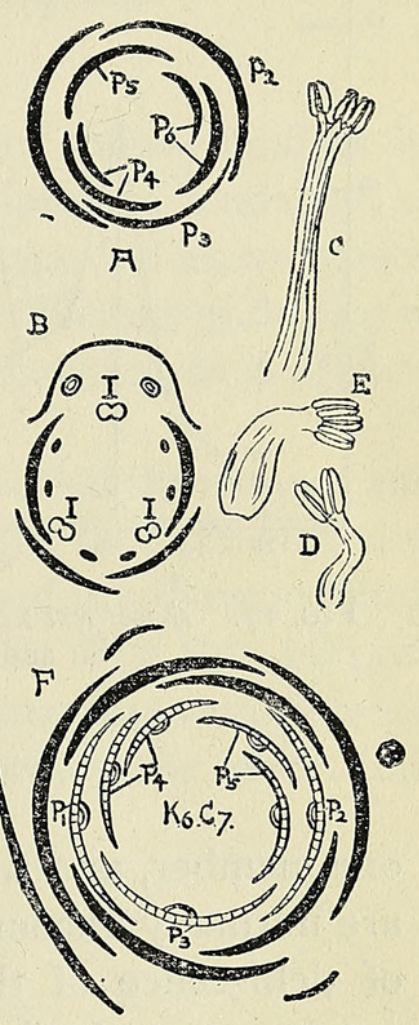

FIG. I6. A, diagram of perianth of $A$. nemorosa; B, floral diagram of Aconitum napellus; $\mathrm{C}$, branched stamen of Aquilegia sp.; $\mathrm{D}$ and $\mathrm{E}$, branched stamens of Delphinium sp.; $\mathrm{F}$, diagram of perianth of Ramun. culus bulbosus. 
IV. Aconitum napellus, L., and A. Lycoctonum, L.

(a) Aconitum napellus. The fact that the gynaeceum of this species normally exhibits three carpels suggested that even here, despite the obvious specialization of the flower, the trimerous tendency might extend to the androecium.

Eighty specimens of this flower were dissected and in every case the outer perianth was composed of five members. The inner whorl, inclusive of the two nectaries, consisted of eight, or more rarely seven, six, or three members. Seventy-three flowers possessed a gynaeceum of three carpels, whilst the remaining seven had two perfect carpels. In two of these latter the third carpel was represented by a dwarfed rudiment devoid of ovules. Clearly, then, we can attribute the bicarpellary condition to the abortion of

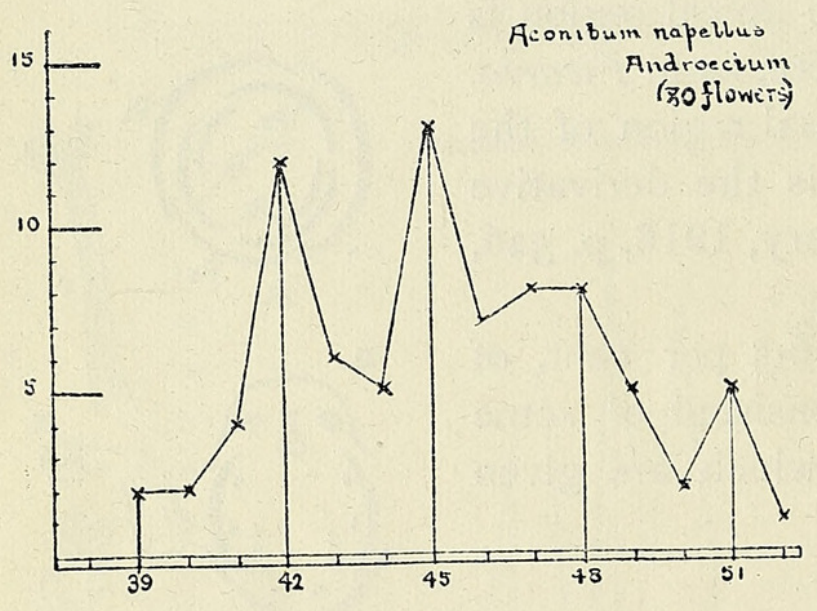

FIG. I7. Aconitum napellus, variation 'curve' for androecium.

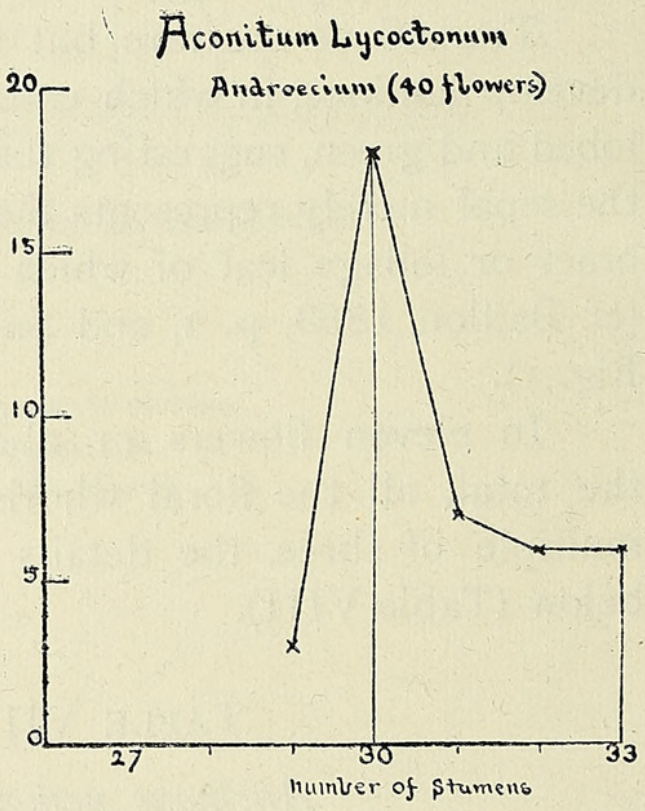

FIG. 18. Variation 'curve' for the androecium of Aconitum Lycoctonum.

one member, and we may note that all conditions from three to one carpel are normally encountered in the genus Delphinium. A study of the order of dehiscence of the stamens shows that the first to mature constitute a trimerous whorl (cf. Fig. I6, B, I, I, I), of which one member is situated opposite the hood and the two others opposite the gaps between the lateral and ventral sepals.

The variation 'curve' for the total number of stamens (Fig. I7) shows a range from thirty-nine to fifty-two, with prominent maxima at forty-two, forty-five, and fifty-one and an indication of a maximum at forty-eight. Here too, then, the minimum number is a multiple of three and the primary and secondary maxima indicate quite clearly variations around primary and secondary modes corresponding to multiples of that number. As in other Ranunculaceous flowers the actual phyllotaxis of the androecium is doubtless 
but an expression of the various mechanical forces in the developing bud, and can give us no clue to the primitive construction of the flower; but the order of dehiscence and the arbitrary recurrence of certain numbers cannot be explained on purely mechanical grounds and must be construed as of phylogenetic import.

(b) Aconitum Lycoctomum. The androecium of this species was examined in forty unopened flower-buds obtained from wild plants in Switzerland by Prof. F. E. Fritsch. From the variation 'curve' given in Fig. 18 it will be seen that the range is narrow and that in the majority of cases the number of stamens was thirty. The lower limit observed was twenty-nine, but Eichler (1875, p. 164, Fig. 67) figures a specimen with only twenty-seven stamens. The large proportion of examples with thirty-three stamens is strongly suggestive of a second maximum. In all the flowers examined the gynaeceum consists of three carpels, so that the trimerous tendency is here even more marked than in its congener, a fact that may not be without significance in view of the greater specialization of $A$. napellus.

\section{AQuilegia vulgaris, L.}

We have assumed that where a frequency 'curve' shows maxima at multiples of three the explanation lies in an innate trimerous tendency, as a consequence of which the variation 'curve' is to be regarded as composed of a series of subsidiary variation 'curves' around the different multiples of three, each, however, of diminished prominence in proportion as it departs from the primary mode.

It is well known that the flower of Aquilegia is whorled throughout and is typically pentamerous in structure, and it was thought that the variation in the number of the carpels might afford corroboration of the above assumption by the presence of maxima at multiples of five. For this purpose 300 flowers were examined, and it was found that two maxima were present, namely, at five and ten (cf. Table IX). Even here, however, the lower limit was three carpels.

\begin{tabular}{|c|c|}
\hline Number of Carpels. & Number of Specimens. \\
\hline $\begin{array}{l}3 \\
4\end{array}$ & $\begin{array}{l}3 \\
3\end{array}$ \\
\hline $\begin{array}{l}4 \\
5\end{array}$ & 202 \\
\hline 6 & $3^{\circ}$ \\
\hline 7 & 22 \\
\hline$\delta$ & 13 \\
\hline 9 & 6 \\
\hline IO & 20 \\
\hline I I & 0 \\
\hline I 2 & 0 \\
\hline I 3 & I \\
\hline
\end{tabular}

As in the essentially trimerous flowers we have been considering the stamens are often not a multiple of three, so too here the number of stamens 
is often not a multiple of five. Moreover, the same explanation can be advanced since partially branched stamens (cf. Fig. I6, C) are sometimes encountered and indicate the tendency towards fission of primordia.

\section{Various other Ranunculaceae.}

(a) Delphinium sp. Fifty flowers of a species of Delphinium belonging to the section Staphisagria with three, or rarely two, carpels were dissected, and in two examples branched stamens were observed. In the one case three anthers were present on the same filament and in the second instance two (cf. Fig. I6, D and E).

The number of stamens was most frequently thirty-two, this being the case in thirteen specimens. Seven flowers had thirty stamens and eight

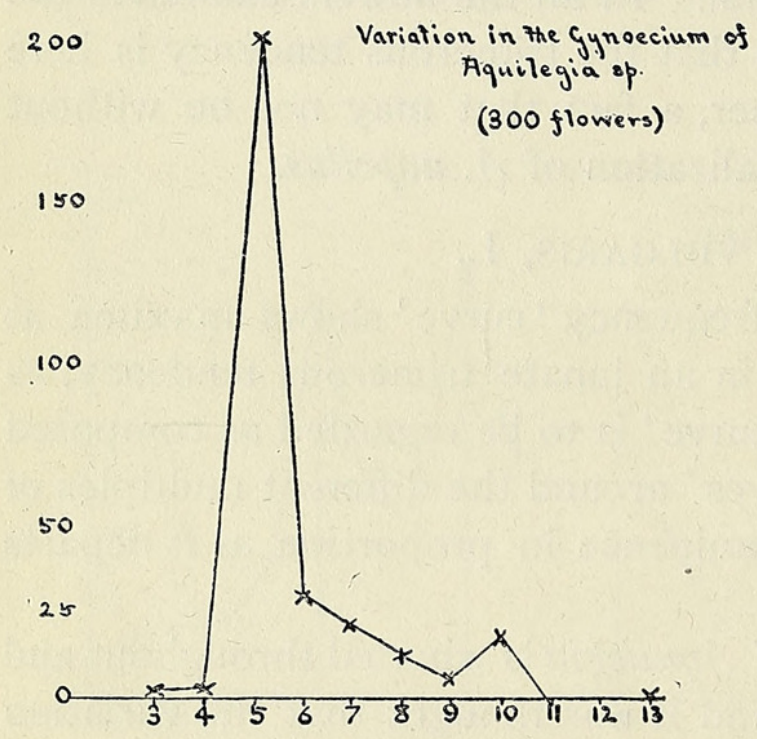

FIG. I9. Variation 'curve' for the gynaeceum of Aquilegia sp. had thirty-three. If one may judge by this small number, the mode is here not a multiple of three, but it is significant that the minimum number of stamens was twenty-seven and the number of carpels almost invariably three.

In one specimen six inner perianth segments were present, in place of the normal four, but since the androecium consisted of thirtythree stamens the increase cannot be attributed to transformation. The facts, then, seem to warrant the assumption that, here too, fission of both perianth and staminal rudiments takes place as in other members of this family.

(b) Ramunculus bulbosus. Out of several hundred flowers of this species forty-one exhibited supernumerary members in one or other whorl of the perianth. The details of these specimens are given in Table $\mathrm{X}$. It will be noted that in only one instance was the increased number of petals associated with a diminished number of sepals, and, further, that an increase in the number of sepals was, in every case, accompanied by an increase in the number of petals. The additional sepals may therefore be regarded as the result of fission of the original sepal rudiments. The same explanation can be applied to the corolla, for we find that large numbers of petals are almost invariably associated with an increased number of stamens, as indicated by the following floral formulae of some conspicuous examples :

$$
\begin{aligned}
& \mathrm{K}_{5}, \mathrm{C} 6, \mathrm{~A}_{61}, G 3^{6} \\
& \mathrm{~K} 5, \mathrm{C} 8, \mathrm{~A}_{54}, G 37 \\
& \mathrm{~K} 6, \mathrm{C} 7, \mathrm{~A}_{7}, G 37 \\
& \mathrm{~K} 6, \mathrm{C} 5, \mathrm{~A} 60, G 4^{\mathrm{I}}
\end{aligned}
$$


In addition the orientation of the supernumerary petals is quite consistent with their origin by fission (cf. Fig. I6, F, P4 and P5).

TABLE X.

Ramunculus bulbosus.

Number of Sepals.

Number of Pelals.

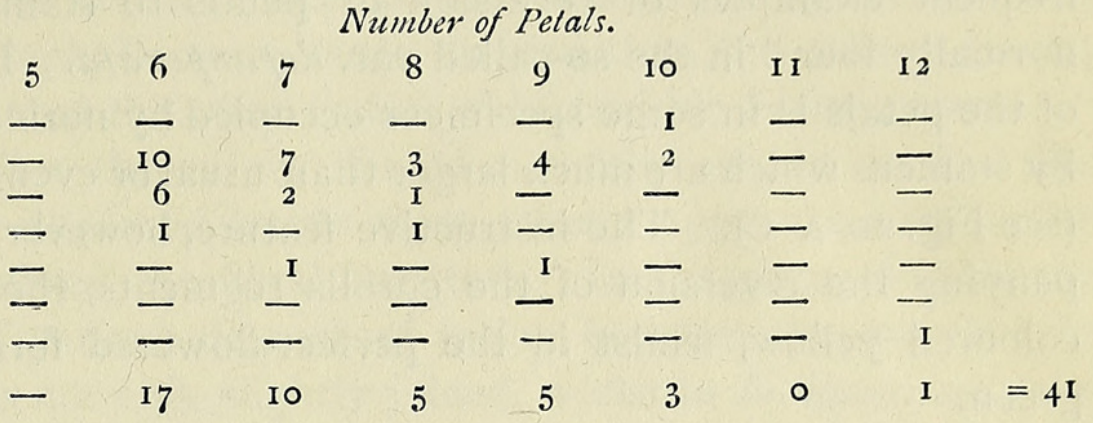

A very significant feature, which emphasizes not only the distinction between calyx and corolla but also the essentially foliar character of the former, is the fact that in three out of the fourteen flowers with extra sepals, the number of peduncular ridges corresponded to the number of calyx segments. But in no case were additional ridges present when the sepals numbered five whatever the increase might be in the number of corolla segments. Coloured sepals are occasionally met with (cf. Leavitt, 1909).

(c) Ramunculus acris. Seventy flowers of this species were dissected and showed a wide range of variability as regards the number of parts present. The minimum observed was seventy-nine and the maximum 275 . The sepals varied in number from five to twelve, the petals from five to thirteen, the stamens from forty-four to 167 , and the carpels from fourteen to eighty-three. Such extraordinary fluctuation would necessitate

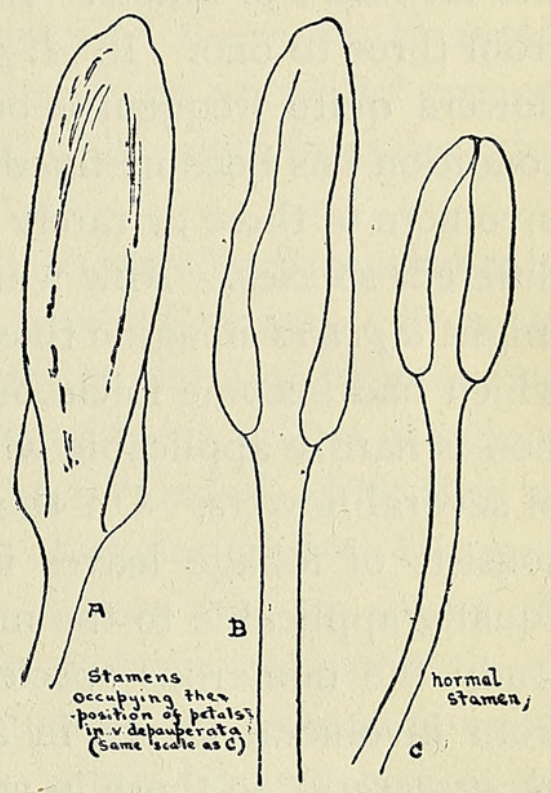

FIG. 20. Stamens of Ranunculus auricomus, var. depauperata, developed in place of the petals. the examination of a far larger number of specimens before any conclusions could be drawn regarding the existence of any trimerous or pentamerous tendency. But the data are sufficient to show that each region tends to vary meristically in the same sense. In the extreme example referred to above the floral formula was $\mathrm{K}$ I2, $\mathrm{C}$ I3, A $167, G 83$. In no instance was an increase in the number of sepals accompanied by a decrease in the number of petals. Evidence for the origin of supernumerary petals by fission is afforded by the occurrence of cleft or trilobed corolla segments. Petaloid stamens were observed in a few 
specimens, and coloured sepals, though rare, were also noted. The latter, however, never show any indication of a nectary and can be readily distinguished from virescent petals. In one example a sepal was present which bore at the apex a small trilobed lamina.

(d) Ranunculus auricomus. This species is interesting as it affords frequent examples of reversion of petals to stamens. This condition is normally found in the so-called var. depauperata. In this form the position of the petals is in some specimens occupied by normal stamens, but in others by stamens which are much larger than usual or even subpetaloid in character (see Fig. 20, A-C). The instructive feature, however, is the fact that, accompanying the reversion of the corolla segments, the sepals usually become coloured yellow, whilst in the perfect-flowered form the sepals are quite green.

\section{ViI. The Origin of the Perianth.}

There can be little doubt that the solitary inflorescence of Anemone has been derived by reduction from a, many-flowered inflorescence. Thus, in Anemone narcissiflora two to six flowers arise together in an umbel from the involucre of bracts. In $A$. ranunculoides the number of flowers varies from three to one. In $A$. palmata the flower is normally solitary, but two flowers quite frequently occur, whilst in $A$. nemorosa the single-flowered condition has become fixed. In all these cases the flowers arise from an involucre of three or rarely four leaves which is obviously homologous in the different species. Now whilst in the case of the single-flowered members we might a priori imagine these bracts to represent descended perianth leaves which had become foliaceous, as Worsdell maintains (1916), such a conception is hardly applicable where we find the involucre surrounding a group of several flowers. On the other hand, the assumption that the involucre consists of foliage leaves is in complete harmony with all the facts and equally applicable to the many- or few-flowered inflorescence. Again, if we study the numerous species of Anemone we find almost every transition from involucral leaves in all respects resembling the foliage leaves (e.g. $A$. nemorosa), to those in which the involucral leaves are essentially calyxlike and closely approximated to the flower (e.g. A. hepatica). It is, moreover, significant that in general where the involucre is situated close to a flower its members depart farther from the foliaceous type than where it is more remote.

Now this transition can of course be viewed from either direction, but if the bracts forming the involucre are only modified stamens it is scarcely conceivable that their ultimate development should present all the indications of homology with, rather than analogy to, the foliage leaves. If such a striking parallel evolution had actually taken place, it could only indicate an identity of function. Yet if we examine species of Anemone with a simple type of leaf but in which the involucre is not in close proximity to 
the flower (e.g. A. palmata), we find that the involucral leaves partake of the dissected, probably ancestral, foliar type and do not resemble the simple foliage of the species-a fact that cannot be explained on any other hypothesis than the common origin, and therefore phylogeny, of both bracts and foliage.

In Ramunculus acris Goebel $(1905, \mathrm{p} .393)$ was struck by the unusual condition that the hypsophylls were more divided than the foliage leaves, and we have already noted the same feature exhibited by Ficaria verna.

Again, on the foliar theory we should naturally expect to find the involucre of upwardly displaced leaves more closely approximated to the flower the more specialized the floral structure. In the genus Nigella the different species show various degrees of fusion between the carpels; in $N$. arvensis the carpels are only slightly joined, whilst in $N$. damascena the fusion is complete. In the former the involucre is remote from the flower, in the latter closely approximated to it.

If we accept the view that this involucre is directly derived from sporophylls then we have the anomaly of the least specialized involucre associated with the most specialized gynaeceum and vice versa.

There can be little doubt that the involucres of Anemone, Eranthis, and Nigella are homologous structures, and there are no adequate grounds for regarding the involucre of $A$. hepatica as distinct in origin from the calyx of Ramunculus ficaria.

Various writers have pointed out that the Ranunculaceae present us with almost all stages in the development of petaloid stamens, from the nectariferous staminodes of Anemone pulsatilla to the petal of Ramunculus.

If we hold that the perianth is entirely staminodal (cf. de Candolle, 1823 ; Drude, 1887; Celakovsky, 1896 and 1900; Worsdell, 1903) then we must assume that two totally uncorrelated lines of evolution from the same type of structure are presented to us. For in Ranunculus or any of the Helleboreae we must assume that, first, the non-nectariferous perianth was developed from the sporophylls and that subsequently from the same origin a completely distinct type, the nectariferous petal, became elaborated. Moreover, there is no relation between the specialization of the non-nectariferous perianth and the development of the honey-leaves. In Anemone pulsatilla we find a highly specialized coloured perianth, together with the simplest type of nectar-secreting staminode, and in the Helleboreae the more advanced type of flower of Helleborus has a less specialized honeyleaf than Eranthis.

If we now turn to the mode of arrangement of the perianth segments we find that in the Clematideae the calyx usually consists of four members (arising as two pairs, cf. Payer, 1857, p. 252) corresponding to the four orthostichies of the decussately arranged leaves of the adult plant. In the other tribes, where the leaves are alternate and generally exhibit a one-third 
or two-fifths phyllotaxis, the calyx commonly consists of from three to five members. Such correspondence between the orthostichies of the vegetative leaves and calyx-segments has no significance unless the latter be derived from the former, since the staminal orthostichies are usually much more numerous. The case of Clematis alpina might be regarded as an exception, since here there are four staminodal petals alternating with the four sepals. But the spacial relations here determine the position of the inner whorl just as they determine that of the corolla in Ranunculus or of the stamens in Rosaceae. Such an explanation cannot, however, be applied to the outermost whorl.

It is, therefore, obvious that to regard the perianth as an homologous structure derived from the stamens involves us in several assumptions for which there appears no warrant. On the other hand, these very difficulties fall into place if we accept the view that the perianth is in some cases (e. g. Anemone) entirely foliar in origin (cf. Prantl, 1887) and in others (e. g. Ficaria) derived partly by modification of leaves (the calyx) and partly from sporophylls (the corolla) (cf. Grant Allen, 1882).

Great stress has been laid by some writers on the existence in this group of polymerous perianths (Worsdell, 1916, p. I29), the argument being briefly that the supernumerary perianth segments could not have arisen de novo and must therefore be regarded as transformed stamens. That fission is a common phenomenon in the calyx of the Ranunculaceae, as also in the other floral whorls, has been amply demonstrated in the foregoing pages. As pointed out by de Vries (1893), the unilateral character of the Galtonian half-curves, as exhibited in the perianth variation of Caltha palustris or Ranunculus bulbosus, can be explained if we assume increase to be due to dédoublement. The same feature is also encountered in allied families ; for example, Marchand (1863, p. I27) recorded the occurrence of dédoublement in the androecium of Epimedium musschianum, extreme examples exhibiting eight stamens in place of the usual four. The structure of the normal flower of Podophyllum peltatum illustrates fission both in the androecium and perianth.

Polymerous perianths can therefore be best explained as due to fission (cf. also Rendle, 1903), and the fact that increase in their members is usually accompanied by an increase rather than a decrease in the androecium renders the transformation theory in the highest degree improbable.

It has been shown that there is a fairly widespread tendency for the androecium and gynaeceum in this group to consist of parts which number some multiple of three, and examination of the variation 'curve' renders it very probable that this feature is the result of a trimerous tendency (cf. p. 64). It seems most likely, then, that an arrangement of parts on six or three orthostichies was primitive for the group, but owing to increase in the number of members through fission this arrangement has become obscured. 
Such increase has resulted in mechanical pressure, which in turn has produced displacement, so that a high phyllotaxy has resulted. Perhaps, too, shortening of the torus has contributed to this effect. As already pointed out, this interpretation harmonizes with the fact that trimerous flowers are frequent amongst the Ranales as a whole and particularly associated. with the less specialized and arboreal forms.

The view here put forward is, then, that the primitive Ranunculaceous flower exhibited an androecium and gynaeceum of members either arranged in alternating whorls of three members each or on six orthostichies and probably borne on an elongated axis. The essential organs were surrounded by a perianth of foliar origin also consisting of trimerous whorls. From this condition both the pentamerous calyx of Ranunculus and tetramerous calyx of Clematis have been derived, whilst the more primitive perianth of two trimerous whorls is seen in Eranthis and Anemone spp. What was perhaps the early Ranunculaceous type is seen in some species of Magnolia in which the whole floral structure is composed of alternating trimerous whorls.

As a subsequent specialization the outermost stamens have in some cases developed as an attractive whorl (e. g. Ramunculus, \&c.), but in others foliar perianth members are alone present and perform both functions of protection and attraction (e.g. Anemone pulsatilla).

The occurrence of trimery and androecial fission as a feature of the Ranunculaceae is all the more interesting as both are found in the Alismaceae, to which Monocotyledonous family the Ranunculaceae exhibit so many resemblances.

\section{Summary.}

The variations, both meristic and substantive, in the flowers of Eranthis hyemalis, Ficaria verna, and other members of the Ranunculaceae, are described and the following facts established:

(I) Meristic variation is exhibited in all the floral regions, involving a corresponding variation in the total number of parts present.

(2) There is usually an obvious correlation between the variation in the different parts of the flower, and, in general, increase or decrease is exhibited simultaneously by the perianth, androecium, and gynaeceum.

(3) Branched stamens are not infrequently present, and bifurcated petals have been observed in several members of the group. Branched carpels are recorded for Helleborus.

(4) The position of the supernumerary perianth segments is consistent with their origin by fission.

(5) The two-whorled trimerous perianth of Eranthis, Anemone, \&c., is sometimes replaced by a pentamerous whorl exhibiting the quincuncial arrangement, a change that can be attributed to fusion between one member of the outer whorl with one of the inner. 
(6) Increase in any one region is usually accompanied by increase in the adjacent regions, so that transformation cannot be assumed.

(7) In several members of the Ranunculaceae belonging to different tribes and genera the 'curve' of meristic variation for the androecium and gynaeceum exhibits several maxima which correspond to numbers that are some multiple of three. The minimum number of parts present is often also a multiple of the same number.

(8) Substantive variations of the nature of transitions are not infrequent and emphasize the foliar nature of the calyx, as in Ficaria and Ramunculus, and of the entire perianth in Eranthis, Anemone, \&c. Still others occur which emphasize the staminodal character of the honey-leaves.

The facts adduced appear to warrant the following theoretical conclusions :

(a) Meristic variation is mainly the outcome of two tendencies, viz. fission and fusion.

(b) The supernumerary perianth members are usually the result of fission, and only very rarely, in the case of staminodal corollas, do we find any evidence of increase as a result of transformation.

(c) Decrease in number is usually the result of fusion (e. g. Anemone, Paeonia), more rarely of suppression (e.g. gynaeceum of Aconitum).

(d) The perianth is either derived entirely from modified foliage leaves (e.g. Anemone, Eranthis, \&c.) or in part from bracts and in part from stamens (e.g. Ranunculus, Clematis alpina, \&c.).

(e) The flower of the Ranunculaceae is probably derived from a trimerous type, which has, however, in many cases become obscured by multiplication of parts and consequent changes in phyllotaxy, or by fusion and abortion.

\section{BiBLiOgRAPHY.}

Allen, Grant (1882): The Colours of Flowers.

Balllon, H. (1862): Sur la fleur des Pivoines. Adansonia, vol. iii, pp. 45-9. (1863): Mémoire sur la famille des Renonculacées. Ibid., vol. iv, pp. I-57.

de Candolle, A. P. (1823): Théorie élémentaire de la botanique. Paris.

Celakovsky, L. (1896 and 1900): Ueber den phylogenetischen Entwickelungsgang der Bliithe und über den Ursprung der Blumenkrone. Sitzungsber. d. k. böhmischen Ges. d. Wiss.

Church, A. H. (1908): Types of Floral Mechanism. Oxford.

CLOS, D. (1852): Étude organographique de la Ficaire. Ann. des Sci. Nat., Bot., $3^{\mathrm{e}}$ sér., vol. xvii, pp. $129-4^{2}$.

Drude, O. (1887): Die systematische und geographische Anordnung der Phanerogamen. Schenk's Handbuch, vol. iii, pt. 2.

Eichler, A. W. (1875-8): Blïthendiagramme. Leipzig.

Elmore, C. J. (1915): Staminate Flowers in Anemone. Bot. Gaz. 
Goebel, K. (1905) : Organography. Vol. ii, Eng. ed., Oxford.

Gwynne-Vaughan, D. T. (1897): On some Points in the Morphology and Anatomy of the Nymphaeaceae. Trans. Linn. Soc. Bot., vol. v, pp. 287-99.

Irmisch, T. (1860) : Ueber einige Ranunculaceen. III. Eranthis hyemalis. Bot. Zeit., pp. 22 I-6. Leavitt, R. G. (1909): Homoeosis in Plants. Bot. Gaz.,"p. 4I, Fig. 7.

Marchand, L. (1863): Sur les fleurs monstrueuses d'Epimedium. Adansonia, vol. iv, p. 127.

PAYER, J. B. (1857): Traité d'Organogénie comparée de la fleur. Paris.

Prantl, K. (1887): Beiträge zur Morphologie und Systematik der Ranunculaceae. Eng. Bot. Jahrb., vol. ix.

Rendle, A. B. (1903): The Origin of the Perianth in Seed Plants. New Phytologist, vol. ii, pp. $66-\eta^{2}$.

Salisbury, E. J. (1916): Variations in Anemone nemorosa. Ann. of Botany, vol. xxx, pp. 525-8. Ecology, p. I 25 .

Smith, T. C. (1893) : Yorkshire Naturalist. p. 246.

DE VRIEs, H. (1893) : Les Demi-courbes Galtoniennes. Arch. Néerlandaises, t. xxviii, pp. 442-57. (1906): Species and Varieties, their Origin by Mutation. 2nd Eng. ed., Chicago.

Worsdell, W. C. (1903): The Origin of the Perianth of Flowers. New Phytologist, vol. ii, pp. $43^{-8}$.

(1906): Principles of Teratology. Vol. ii, Ray Society.

YuLe, G. U. (1902): Variation in the Number of Sepals in Anemone nemorosa. Biometrika. 


\section{$2 \mathrm{BHL}$ Biodiversity Heritage Library}

Salisbury, E. J. 1919. "Variation in Eranthis hyemalis, Ficaria verna, and other members of the Ranunculaceae, with special reference to trimery and the origin of the perianth." Annals of botany 33, 47-79.

https://doi.org/10.1093/oxfordjournals.aob.a089702.

View This Item Online: https://www.biodiversitylibrary.org/item/235681

DOI: https://doi.org/10.1093/oxfordjournals.aob.a089702

Permalink: https://www.biodiversitylibrary.org/partpdf/320244

\section{Holding Institution}

Smithsonian Libraries

\section{Sponsored by}

Biodiversity Heritage Library

\section{Copyright \& Reuse}

Copyright Status: Not in copyright. The BHL knows of no copyright restrictions on this item.

This document was created from content at the Biodiversity Heritage Library, the world's largest open access digital library for biodiversity literature and archives. Visit BHL at https://www.biodiversitylibrary.org. 